\title{
The Paradox of Declining Female Happiness
}

\author{
Betsey Stevenson \\ The Wharton School \\ University of Pennsylvania \\ CESifo and NBER \\ Justin Wolfers \\ The Wharton School \\ University of Pennsylvania \\ CESifo and NBER
}

May 2009

Working Paper 2009-11

http://www.frbsf.org/publications/economics/papers/2009/wp09-11bk.pdf

The views in this paper are solely the responsibility of the authors and should not be interpreted as reflecting the views of the Federal Reserve Bank of San Francisco or the Board of Governors of the Federal Reserve System. 


\title{
The Paradox of Declining Female Happiness*
}

\author{
Betsey Stevenson \\ The Wharton School \\ University of Pennsylvania \\ CESifo and NBER \\ betsey.stevenson@wharton.upenn.edu \\ http://bpp.wharton.upenn.edu/betseys
}

\author{
Justin Wolfers \\ The Wharton School \\ University of Pennsylvania \\ CESifo, CEPR, IZA and NBER \\ jwolfers@wharton.upenn.edu \\ http://www.nber.org/ jwolfers
}

\begin{abstract}
By many objective measures the lives of women in the United States have improved over the past 35 years, yet we show that measures of subjective well-being indicate that women's happiness has declined both absolutely and relative to men. The paradox of women's declining relative wellbeing is found across various datasets, measures of subjective well-being, and is pervasive across demographic groups and industrialized countries. Relative declines in female happiness have eroded a gender gap in happiness in which women in the 1970s typically reported higher subjective well-being than did men. These declines have continued and a new gender gap is emerging-one with higher subjective well-being for men.
\end{abstract}

This draft: May 12, 2009

Keywords: Subjective well-being, life satisfaction, happiness, gender, job satisfaction, women's movement.

JEL codes: D6, I32, J1, J7, K1

\footnotetext{
${ }^{*}$ We would like to thank Amanda Goodall, Christian Holzner, Robert Jäckle, Andrew Oswald, Eric Posner, Cass Sunstein, David Weisbach and seminar participants at the American Law and Economics meetings, UC Berkeley, Brigham Young University, University of British Columbia, Case Western Reserve University, CESifo/Munich University, University of Chicago, Conference on Empirical Legal Studies, Cornell Law School, Dartmouth, Florida International University, Harvard, Institute for International Economic Studies at Stockholm University, the Kiel Institute, the University of Linz, University of Miami School of Business, University of Oslo, University of Pennsylvania, Rice University, Swedish Institute for Social Research at Stockholm University, the San Francisco Federal Reserve Bank, Temple, University of Texas at Houston, and Yale Law School for useful comments and discussions.
} 


\section{Introduction}

By many measures the progress of women over recent decades has been extraordinary: the gender wage gap has partly closed; educational attainment has risen and is now surpassing that of men; women have gained an unprecedented level of control over fertility; technological change in the form of new domestic appliances has freed women from domestic drudgery; and women's freedoms within both the family and market sphere have expanded. Blau's 1998 assessment of objective measures of female well-being since 1970 finds that women made enormous gains. Labor force outcomes have improved absolutely, as women's real wages have risen for all but the least educated women, and relatively, as women's wages relative to those of men have increased for women of all races and education levels. Concurrently, female labor force participation has risen to record levels both absolutely and relative to that of men (Blau \& Kahn, 2007). In turn, better market outcomes for women have likely improved their bargaining position in the home by raising their opportunities outside of marriage.

Given these shifts of rights and bargaining power from men to women over the past 35 years, holding all else equal, we might expect to see a concurrent shift in happiness toward women and away from men. Yet we document in this paper that measures of women's subjective well-being have fallen both absolutely and relatively to that of men. While the expansion in women's opportunities has been extensively studied, the concurrent decline in subjective well-being has largely gone unnoted. One exception to this is Blanchflower and Oswald (2004), who study trends in happiness in the United States and Britain noting that, while women report being happier than men over the period that they examine, the trend in white women's happiness in the United States is negative over the period. We will show in this paper that women's happiness has fallen both absolutely and relative to men's in a pervasive way among groups, such that women no longer report being happier than men and, in many instances, now report happiness that is below that of men. Moreover, we show that this shift has occurred through much of the industrialized world.

Social changes that have occurred over the past four decades have increased the opportunities available to women and a standard economic framework would suggest that these expanded opportunities for women would have increased their welfare. However, others have noted that with the expansion of opportunities have come costs and that men may have been the beneficiaries of the women's movement. In particular, many sociologists have argued that women's increased opportunities for market work have led to an increase in the total amount of work that women do. 
Arlie Hochschild's and Anne Machung's The Second Shift (1989) argued that women's movement into the paid labor force was not accompanied by a shift away from household production and they were thus now working a "second shift". However, time use surveys do not bear this out. Aguiar and Hurst (2007) document relatively equal declines in total work hours since 1965 for both men and women, with the increase in hours of market work by women offset by large declines in their non-market work. Similarly, men are now working fewer hours in the market and more hours in home production. Blau (1998) points to the increased time spent by married men on housework and the decreased total hours worked (in the market and in the home) by married women relative to married men as evidence of women's improved bargaining position in the home. However, it should be noted that the argument went beyond counting hours in The Second Shift. Women, they argued, have maintained the emotional responsibility for home and family: a point that is perhaps best exemplified by the familiar refrains of a man "helping" around the house or being a good dad when "babysitting" the kids. Thus even if men are putting in more hours, it is difficult to know just how much of the overall burden of home production has shifted, as measuring the emotional, as well as physical, work of making a home is a much more difficult task. A recent paper by Alan Krueger (2007) sheds some light on this issue by examining the degree of pleasantness and unpleasantness in daily activities. Assuming that one's enjoyment of particular activities has not changed over time; he finds that women's new mix of daily activities leaves them hedonically unchanged. However, men have had a net increase in the pleasantness of activities in their day. Thus, according to Krueger's estimates, between 1966 and 2005, relative to men, women became hedonically worse off.

Social and legal changes have given people more autonomy over individual and family decision making, including rights over marriage, children born out of wedlock, the use of birth control, abortion, and divorce (Stevenson and Wolfers, 2007). Once again, men may have been able to disproportionately benefit from these increased opportunities: Akerlof, Yellen, and Katz (1996) argue that sexual freedom offered by the birth control pill benefited men by increasing the pressure on women to have sex outside of marriage and reducing their bargaining power over a shotgun marriage in the face of an unwanted pregnancy. During this period there have also been large changes in family life. Divorce rates doubled between the mid-1960s and the mid-1970s, and while they have been falling since the late 1970s, the stock of divorced people has continued to grow (Stevenson and Wolfers, 2007). In addition to divorce, there has been an increase in the rate of children born out of wedlock that was concentrated in the 1960s and early 1990s. As a result of increases in both divorce and out-of-wedlock childbearing by age 15 about half of all children in the US are no longer living with both biological parents (Elwood \& Jencks, 2001). These changes have, however, disproportionately 
impacted non-white women and white women with less education (Elwood and Jencks 2001; Isen and Stevenson 2008) and thus, if the decline in women's happiness is related to these trends, we should expect to see greater happiness declines among these women.

Both men and women in the U.S. have faced some other challenging societal trends in the past 30 years as well. While the male-female wage gap converged over this period, income inequality rose sharply through the 1980s and has continued to rise, albeit more slowly, in recent decades. Moreover, the real wages of many men fell during much of this period. In particular, real wages for men with less than a college degree fell from 1979-1995 (Autor, Katz, \& Kearney, 2008). Many households experienced only moderate growth in household income, with those in the bottom half of the income distribution experiencing real growth of less than 0.5\% a year from 1973 to 2005 (Goldin and Katz, 2007) and much of this increase was due to the additional earnings of wives. Along with this rise in income inequality has come concerns about increasing income volatility, and a more general concern about households bearing more health and retirement risk (Hacker, 2007). While these trends have impacted both men and women, it is possible that the effect of these trends on happiness has differed by gender.

Even if women were made unambiguously better off throughout this period, a richer consideration of the psychology behind happiness might suggest that greater gender equality may lead to a fall in measured well-being. For example, if happiness is assessed relative to outcomes for one's reference group, then greater equality may have led more women to compare their outcomes to those of the men around them. In turn, women might find their relative position lower than when their reference group included only women. This change in the reference group may make women worse off or it may simply represent a change in their reporting behavior. An alternative form of referencedependent preferences relates well-being to whether or not expectations are met. If the women's movement raised women's expectations faster than society was able to meet them, they would be more likely to be disappointed by their actual experienced lives. As women's expectations move into alignment with their experiences this decline in happiness may reverse. A further alternative suggests that happiness may be driven by good news about lifetime utility (Kimball \& Willis, 2006). Under this view, the salience of the women's movement fuelled elation in the 1970s that has dissipated in the ensuing years.

Alternatively, women's lives have become more complex and their well-being now likely reflects their satisfaction with more facets of life compared with previous generations of women. For example, the reported happiness of women who are primarily homemakers might reflect their 
satisfaction with their home life to a greater extent compared with women who are in both the labor force and have a family at home. For these latter women, reported happiness may reflect aggregating over their multiple domains. While this aggregation may lead to lower reported happiness, it is difficult to know whether this reflects a truly lower hedonic state. There are significant data limitations in testing this theory, as, ideally, one would want a series of questions that asked both about one's satisfaction in various domains and the relative importance of that domain to one's life. In Section IV we explore the extent to which questions about domain specific satisfaction and the importance attached to various life domains can shed light on the relative decline in women's reported happiness.

Our contribution in this paper is to carefully document trends over several decades in subjective well-being by gender in the United States and other industrialized countries, collecting evidence across a wide array of datasets covering various demographic groups, time periods, countries, and measures of subjective well-being. To preview our findings, section II shows that women in the United States have become less happy, both absolutely and relative to men. Women have traditionally reported higher levels of happiness than men, but they are now reporting happiness levels that are similar or even lower than those of men. The relative decline in well-being holds across various datasets, and holds whether one asks about happiness or life satisfaction. In section III we explore these trends by demographic group, finding that the relative decline in women's well-being is ubiquitous, and holds for both working and stay-at-home mothers, for those married and divorced, for the old and the young, and across the education distribution. While compositional shifts in these groups make it difficult to interpret trends for each group, the fact that we find similar trends across groups leaves little doubt that the decline in female happiness is widespread and cannot be attributed easily to one social phenomenon. For example, decreases in happiness arising due to the "second shift" should impact working mothers more than others. Similarly, declines in happiness stemming from the challenges of single-parenthood should have greater impact on non-white women and white women with less education. Yet, we find no evidence of such differential changes in reported well-being.

We find that these same trends are also evident across those industrialized countries for which we have adequate subjective well-being data. Using data from the Eurobarometer we find across the EU happiness has risen for both men and women, however happiness increases have been greater for men relative to women leading to a decline in European women's happiness relative to that of European men. We analyze trends separately for 12 European countries-Belgium, Denmark, France, Great Britain, Greece, Ireland, Italy, Luxembourg, Netherlands, Portugal, Spain, and West Germany- 
finding relative declines in women's happiness that are similar in magnitude in every country except West Germany. We briefly examine data from a richer set of countries and find that the limited sample size yields extremely wide confidence interval around these country-specific estimates. However, the relative declines found for Europe and the US lie within a 95\% confidence interval of 125 of the 147 we countries we examine.

Finally, Section IV assesses the evolution of satisfaction across a number of domainsmarriage, work, health, and finances - and while women report decreasing satisfaction in some of these domains, typically men report similar, or even more rapid, declines. The one clear exception is that women have become less satisfied with their family's financial situation both absolutely and relative to that of men. Unfortunately most of the available surveys of adults are limited in the extent to which we can assess the satisfaction and importance of multiple domains. Turning to the Monitoring the Future dataset (which surveys American high school students), we find that teenage girls have attached greater importance to a number of domains both absolutely, and relative to that of boys. Moreover, they are increasingly dissatisfied with the amount of free time that they have available, perhaps as a result of their increasing desire to excel in their roles in the community, in the labor force, and in their families.

Our findings hold provocative implications for public policymakers, those interested in gender, and those interested in using subjective well-being measures to assess public policy. Did men garner a disproportionate share of the benefits of the women's movement? Alternatively, perhaps the wellbeing data point to differential impacts of social changes on men and women, with women being particularly hurt by declines in family life, rises in inequality, or reductions in social cohesion. Or one might regard our rather striking observation as an opportunity to better understand the determinants of subjective well-being, and the mapping between responses to survey questions about happiness and notions of welfare.

We highlight a puzzle in trends in women's measured subjective well-being that may be driven by an aggregate change that is impacting women differently than men, a change in the reference group or expectations for women such that their lives are more likely to come up short today than in the past, or finally, may be driven simply by a change in how women answer the question. At this stage, our ambitions are somewhat limited. We do not purport to offer an answer to what is driving the decline in subjective well-being among women. Rather we aim to organize the relevant data, and highlight the robust evidence in favor of a rather puzzling paradox: women's relative subjective well-being has 
fallen over a period in which most objective measures point to robust improvements in their opportunities.

\section{Happiness Trends by Gender}

We examine men's and women's subjective well-being in the United States over the last 35 years using data from the General Social Survey (GSS). This survey is a nationally representative sample of about 1,500 respondents each year from 1972-1993 (except 1979, 1981 and 1992), and continues with around 3,000 respondents every second year from 1994 through to 2004, rising to 4,500 respondents in 2006. ${ }^{1}$ These repeated cross-sections are designed to track attitudes and behaviors among the U.S. population and contain a wide range of demographic and attitudinal questions.

Subjective well-being is measured using the question: "Taken all together, how would you say things are these days, would you say that you are very happy, pretty happy, or not too happy?" In addition, respondents are asked about their satisfaction with a number of aspects of their life such as their marriage, their health, their financial situation, and their job. (We will return to these data on subjective well-being across life domains in section IV.) The long duration of the GSS and the use of consistent survey language to measure happiness make it ideally suited for analyzing trends in wellbeing over time. However, there are a few changes to the survey that can impact reported happiness. For example, in every year but 1972, the question about happiness followed a question about marital happiness and in every year-except 1972 and 1985-the happiness question was preceded by a fiveitem satisfaction scale. Both of these changes have been shown to impact reported happiness (Smith, 1990). We can create consistent data that account for these measurement changes, as the GSS used split-ballot experiments to provide a bridge between different versions of the survey. We make adjustments to the data following the approached detailed in appendix A of Stevenson and Wolfers $(2008 b) .^{2}$ Finally, In order to ensure that these time series are nationally representative, all estimates are weighted (using the GSS weight WTSALL), and we drop the 1982 and 1987 black oversamples. In order to maintain continuity with earlier survey rounds, we also drop those 2006 interviews that

\footnotetext{
${ }^{1}$ Only half the respondents were queried about their happiness in 2002 and 2004, followed by two-thirds in 2006

2 While the split ballot experiments allow a comparison to include the years 1972 and 1985, they also mean that it is not possible to simply drop these two outlier years, as results from subsequent surveys also need to be adjusted for the presence of these experimental split ballots.
} 
occurred in Spanish and could not have been completed had English been the only option, as Spanish language surveys were not offered in previous years. ${ }^{3}$

Beyond measuring subjective well-being consistently, it is useful to consider what it is that a question about happiness is measuring. Although the validity of these measures remains a somewhat open question, a variety of evidence points to a robust correlation between answers to subjective wellbeing questions and more objective measures of personal well-being. For example, answers to subjective well-being questions have been shown to be correlated with physical evidence of affect such as smiling, laughing, heart rate measures, sociability, and electrical activity in the brain (Diener, 1984). Measures of individual happiness or life satisfaction are also correlated with other subjective assessments of well-being such as independent evaluations by friends, self-reported health, sleep quality, and personality (Diener, Lucas, and Scollon, 2006; Kahnman and Krueger, 2006). Self-reports of happiness have also been shown to be correlated in the expected direction with changes in life circumstances. For example, an individual's subjective well-being typically rises with marriage and income growth and falls while going through a divorce. However, it should be noted that subjective well-being is both a function of the individual's personality and his or her reaction to life events. As such, correlations between life outcomes and happiness may not be causal. For example, one reason that married people report substantially greater happiness than unmarried people in a cross-section is because happy people are more likely than unhappy people to marry (Stevenson and Wolfers, 2007)

Figure 1 shows how answers to the happiness question have trended over time for both men and women. The upper panel shows the raw sample proportions, by gender. The top lines show that in the 1970 s women were more likely than men to report being "very happy", while this differential began to evaporate in the 1980s. The bottom two lines show that in the 1970s men and women were roughly equally likely to report being "not too happy" and a gap emerges in the 1990s with women more likely than men to report unhappiness. Thus the decline in women's well-being occurs across the well-being distribution.

The bottom panel combines the data across these categories into a single happiness index by gender, estimated by running an ordered probit on the year*gender fixed effects. The lines plot the estimated happiness index for men and women, while the bars indicated the difference between the two. As has been shown in previous studies (Blanchflower \& Oswald, 2004), women were historically more likely to report higher levels of subjective well-being, yet we see that this happiness gap has

3 This treatment of the data also follows Stevenson and Wolfers (2008b). 
largely reversed as women's reported subjective well-being has fallen over the past 35 years. By the start of the $21^{\text {st }}$ century, women reported happiness levels on par with, or perhaps lower than, those reported by men (precise statements about recent levels are somewhat difficult given the noise in these data). The regression at the bottom of the figure shows that this trend in declining female happiness is statistically significant.

Table 1 embeds these findings in a more formal regression analysis, allowing us to combine the data across these categories into a single happiness index by gender. We estimate a regression of the form

$$
\begin{aligned}
\text { Happiness }_{i, t}= & \alpha+\beta_{1} \text { Female }_{\mathrm{i}}^{*}\left(\text { Year }_{\mathrm{t}}-1972\right) / 100+ \\
& \beta_{2} \text { Male }_{\mathrm{i}} *\left(\text { Year }_{\mathrm{t}}-1972\right) / 100+\beta_{3} \text { Female }_{\mathrm{i}}+\varepsilon_{i, t}
\end{aligned}
$$

where $i$ denotes an individual, and $t$ denotes the year in which that individual was surveyed by the GSS. The results of an ordered probit regression of equation [1] in which the standard errors are clustered at the year level are shown in the first column of Table 1. The regression shows a decline in women's happiness, but very little change in men's reported happiness, indicating that women's happiness has fallen both absolutely and relative to that of men. In Table 1, the fourth row calculates the relative decline in female happiness by showing the estimated difference between the female and male happiness trends.

As was shown in Blanchflower and Oswald (2004) we see a positive and significant coefficient on the female dummy variable indicating that women historically reported higher levels of subjective well-being. The fifth and sixth row of Table 1 report the implied estimates of the gender happiness gap in 1972 and 2006 respectively. At the start of the sample women reported higher levels of subjective well-being than did men, however by 2006 this earlier gap had reversed and women's subjective wellbeing in recent years is lower than that of men.

Thus far we have shown the raw trend in reported happiness by gender, without adding additional controls. The difficulty with adding controls is that most of the things for which one would like to account are not exogenous life events, but rather choices that people make, and importantly, choices that have been changing over our sample period in both likelihood and the selection of individuals making specific choices. However, we can start by adding controls for exogenous compositional shifts in the population. In column 2, dummy variables are added to the ordered probit 
specification for decadal age categories, race, and immigrant status. ${ }^{4}$ The US has undergone large demographic changes over the past 35 years-the population is $4 \frac{1}{2} 2$ years older on average and the non-white population has doubled-however, accounting for these shifts has little impact on the estimated trends in happiness.

The third column of Table 1 adds controls for socioeconomic characteristics such as income, children, employment status, and marital status. These controls are all interacted with gender to allow for the association between these characteristics and happiness to differ for men and women. ${ }^{5}$ Importantly, these controls are not exogenous characteristics assigned by nature, but instead reflect life choices in various domains. Moreover, there have been important shifts in who marries, gets more education, has children, is employed, etc. As such, the relationship between these controls and happiness is likely changing over time due to changing selection into each control category. If instead the estimated coefficients on each of the controls represented the causal relationship between the control variable and happiness, then adding these controls would account for changes in happiness due to changes in these socioeconomic characteristics. However, research has repeatedly shown that these estimates should not be considered fixed causal relationships. ${ }^{6}$ Thus, we add these controls with a note of caution that interpreting happiness trends conditional on endogenous socioeconomic controls is not straightforward. Despite these caveats, the inclusion of these controls has little effect on our estimated trend in the gender happiness gap. The similarity of the estimated trend in the gender happiness gap to that in Column 1 highlights the fact that the relative (and absolute) decline in female happiness is not easily explained by these important, and changing, facets of adults' lives.

The next few columns explore whether the results are robust to alternative specifications. In columns 4 and 5 we run OLS rather than an ordered probit. Happiness is coded as a 1, 2, 3 variable with higher numbers indicating greater happiness. In order to make the coefficients comparable we first standardize the happiness variable by subtracting the mean and dividing by the standard deviation. ${ }^{7}$ Column 4 shows the baseline specification without any additional controls, while Column 5

\footnotetext{
${ }^{4}$ Ethnicity is not available for the entire sample so we do not control for Hispanic in this specification. However, in Table 2 we explore differences by race further and consider a subsample of non-Hispanic whites.

${ }^{5}$ Specifications that simply include each control variable, rather than each control variable and interactions of each control variable with gender, yields very similar results and are thus not shown.

6 For example, Stevenson and Wolfers (2007) show that happier people are more likely to get married, thus accounting for some of the relationship between marital status and happiness.

7 Both ordered probit and OLS on a standardized variable create coefficients that are roughly comparable both with each other and across data sets(the ordered probit standardizes happiness conditional on the covariates, while our standardization for the OLS specification is unconditional). As a result these are our two preferred
} 
adds the full set of control variables. In both cases the estimates are quite similar to those of the ordered probit.

In Columns 6 and 7 we run probit models to explore whether the trends in happiness reflect changes both in the propensity of people to report being "very happy" and "not too happy". ${ }^{8}$ Column 6 shows the results of a probit regression in which the dependent variable is an indicator variable reporting whether the respondent is "very happy". We report probit coefficients (rather than implied percentage point changes) to make the results comparable to the coefficients in columns 1 through 3 , which are also elasticities of a latent standard normal happiness index. The probit coefficient on the female time trend is similar, albeit slightly larger, to that seen for happiness overall in Column 1 , as is the difference between the female and male trends. Evaluating the coefficients at the mean, women begin the sample 4 percentage points more likely to report that they are very happy than men and end the sample 1 percentage point less likely, with the proportion of women reporting they are very happy falling 0.15 percentage points a year relative to men.

Turning to the bottom category we see that women became slightly less likely, albeit statistically insignificantly so, to say that they were "not too happy"; however men became even less likely to be in this category. As such, relative to men, women became more likely to be in the bottom category of happiness. The magnitude of the decline is similar to that seen for happiness overall (albeit inversely signed since this specification assesses unhappiness). Converting this to the proportional changes evaluated at the mean, women were 1 percentage point less likely than men to say that they were not too happy at the beginning of the sample; by 2006 women were 1 percentage point more likely to report being in this category. This smaller shift partly reflects the smaller proportion of respondents in this bottom category. While more of the absolute happiness decline appears to have come from a reduction in women selecting the top happiness category, movement throughout the distribution is consistent with a fall in women's happiness relative to that of men.

In a further set of robustness checks (not shown), we investigate whether the absolute and relative decline in female happiness is occurring throughout the sample period. To test for this we break the sample at various points and estimate equation [1] separately using each of the subsamples. While the estimates obtained in various subsamples differ in the point estimate and the statistical

specifications for dealing with happiness data. For more information on cardinalizing happiness variables see Praag and Ferrer-i-Carbolell (2008).

${ }^{8}$ Results are shown only for the simplest specification for space considerations. Similar results are obtained when we include a full set of control variables. 
significance of the estimated difference between the trends in female and male happiness, we found no time period for which the estimated happiness trends over the full sample were not contained in a $90 \%$ confidence interval. We also test for a trend break in the mid-1980s when female happiness fell below men's for the first time. In none of these specifications did we find a statistically significant trend break that differed for men and women. In addition, we replace the linear trends with quadratic trends. These results also pointed to a decline in women's happiness, both absolutely and relative to that of men. The coefficient estimates suggest that women are getting less happy at a decreasing rate over time although the coefficient on the quadratic term was not significant. The quadratric trend does a better job of explaining the male trend in happiness - men were getting happier at a slightly decreasing rate over time. The linear and quadratric terms for men were both individually and jointly significant. However, a calculation of gender happiness gap over the 35 year period using the quadratic trend estimates yields the aforementioned reversal of the gender happiness gap. Comparing the difference between men's and women's happiness throughout the sample, the result is very similar to that which is seen with a linear trend. Finally, we allow for a completely non-parametric specification of the time trend by controlling for year fixed effects and test for a gender difference in a quadratic term. Again we find results that are qualitatively similar to those seen using a linear trend.

The consistent estimates across all specifications suggest that women have become less happy over time both absolutely and relative to men. However, how much less happy have they become? Given that the dependent variable is qualitative in nature, one must take care in interpreting these magnitudes. In 1972 women were happier than men on average and the median woman was as happy as a man at the 53.3 ${ }^{\text {rd }}$ percentile in the male distribution. By 2006, however, the median woman's happiness was less than that of the median man in 1972, while the median man in 2006 was slightly happier than his counterpart in 1972. Comparing the 2006 medians with the distribution for men in 1972, we see that the median woman in 2006 is as happy as a man at the $48.8^{\text {th }}$ percentile in $1972-$ almost 5 percentage points below her position 34 years prior, while the median man in 2006 is as happy as the man at the $50.7^{\text {th }}$ percentile in 1972.

From 1972 to 2006, women's happiness relative to men's fell by $\left(\beta_{2}-\beta_{1}\right) \Delta t=(-0.294-$ $0.082) *(2006-1972) / 100 \approx 0.13$ points. The ordered probit normalizes the underlying distribution of happiness to have a standard deviation of one, and hence this shift amounts to about one-eighth of the cross-sectional standard deviation of happiness. Of course, the cross-section variation in happiness is much larger than the intertemporal variation, and so the same shift is $1 \frac{1}{2}$ times the standard deviation 
of the aggregate annual gender happiness gap. ${ }^{9}$ To compare this change with other well-known shifters of the happiness distribution, we can consider how large an increase in unemployment would be needed to generate a similar shift in subjective well-being. In a related context, Wolfers (2003) regressed individual happiness against a state's unemployment rate, controlling for state and year fixed effects, finding that a one percentage point rise in a state's unemployment rate leads to a decline in happiness 0.015 points. The ratio between these two estimates suggests that the relative decline in the subjective well-being of U.S. women over the past 35 years is roughly comparable to the effects of an $8 \frac{1}{2}$ percentage point rise in unemployment rates (that is, a rise from, say, $4 \%$ unemployment to $12 \frac{1}{2} \%$ ). An alternative metric comes from the literature assessing the cross-country relationship between happiness and levels of GDP per capita (Deaton 2008; Stevenson and Wolfers 2008a). Across a range of ordered probit regressions of happiness or life satisfaction on the log of GDP per capita, Stevenson and Wolfers (2008a) find coefficient estimates of around 0.4, suggesting that the relative decline in women's well-being over the past 35 years is equivalent to a fall in GDP of 0.32 log points $\left(\Delta y=0.4^{*} 0.32=0.13\right) .10$

Given the large declines seen in the General Social Survey, it is worth analyzing happiness trends in alternative datasets and using alternative measures of well-being. The "Virginia Slims American Women's Opinion Polls" (fielded initially by Harris and Associates, and later by Roper Starch) have asked both women and men about women's issues approximately every 5 years since their inception in 1970, providing us with 7 samples to assess. ${ }^{11}$ The first question on each survey (since 1972) asks respondents about their life satisfaction and Figure 2 summarizes these data in two ways. The dashed lines show the proportion of the population "very satisfied" with their lives, while the solid lines report a well-being index constructed by running an ordered probit regression of life satisfaction on a saturated set of year-by-gender fixed effects; the bars show the implied gender satisfaction gap. These data reveal a strong downward trend in life satisfaction for both men and women. The regression specification shown on the bottom of the graph shows an overall downward

\footnotetext{
${ }^{9}$ The intertemporal variability of the gender happiness gap was computed by running an ordered probit of happiness on the interaction of year and gender fixed effects; this yielded 26 annual (or biennial) observations of the gender happiness gap, and these had a standard deviation of 0.082 .

${ }^{10} \mathrm{An}$ alternative means of assessing the magnitude is to compare the shift to the cut points. Doing this we find that the shift is about $8 \%$ as large as the gap between cut-points in the baseline specification.

${ }^{11}$ Weights are used when provided to ensure that the sample is representative of the US population age 18 and over.
} 
trend that is larger than that observed in the GSS. ${ }^{12}$ However, the decline in happiness is stronger for women, and the magnitude of the difference in the trend in men's and women's subjective well-being is similar to that seen in the GSS.

The other main collection of U.S. happiness data comes from the Monitoring the Future study, which surveys around 15,000 U.S. $12^{\text {th }}$ graders each year about their attitudes and has run since 1976.13 Figure 3 shows that these data suggest that young men have become increasingly happy, while young women have become slightly less happy. While these absolute declines are not as large as that seen among U.S. adults, the difference between these trends implies a large decline in girls' happiness relative to that of boys - a difference that is somewhat larger than that seen among U.S. adults. The larger samples in this data collection yield a less noisy series, suggesting a roughly continuous trend decline in the gender happiness gap. While there is some change in the composition of the sample due to rising high school graduation rates, this is unlikely to explain much of these trends as the relative change in the share of girls reporting that they are very happy is larger than the rise in the proportion of girls staying in school until the $12^{\text {th }}$ grade. ${ }^{14}$ Similar surveys of $8^{\text {th }}$ and $10^{\text {th }}$ graders have also been run since 1991, but interestingly, for those age groups, we find boys and girls both getting happier at roughly equal rates (while for $12^{\text {th }}$ graders, even over this sub-period, we find girls getting less happy relative to boys).

\section{Trends in the Gender Happiness Gap Across Groups}

We now turn to breaking these trends apart by various demographic and socioeconomic groups. While adding controls for race, immigration status, and age had little impact on the overall trend, it is possible that there are important differences in happiness trends for each group. In particular, one might expect differences in the happiness trends observed for blacks. The civil rights movement dramatically expanded the opportunities available to African Americans and, while these improvements are evident in most objective measures, it is useful to consider whether these changes are evident in aggregate trends in subjective well-being. Table 2 examines the gender happiness gap

\footnotetext{
12 We cannot tell whether the differences in the overall trend in well-being reflect differences in the questions asked between the Virginia Slims and GSS data, or other methodological differences.

${ }^{13}$ Sampling weights are used to ensure a nationally representative sample of students each year in the $12^{\text {th }}$ grade.

14 The U.S. Census Bureau (2007) report that the proportion of 18-24 year olds who were high school graduates rose from $82 \%$ of young women in 1976 to $86 \%$ in 2005 , while the proportion of young men who graduated was unchanged at $79 \%$.
} 
separately by race. ${ }^{15}$ Trends in happiness among blacks are examined in columns one and two. These data show that happiness has trended quite strongly upward for both female and male AfricanAmericans, erasing about two-thirds of the large racial differences in subjective well-being that were evident in the early 1970s (Stevenson and Wolfers, 2008b).

However, there is little difference in these trends by gender. Indeed, the point estimates suggest that well-being may have risen more strongly for black women than black men, an outcome that is consistent with other indicators of economic and social progress. While the point estimates suggest that the gender gap in happiness for blacks has increased over this period, the estimated change in the gap is not statistically significant. Moreover, the results on the trend in the gender gap are sufficiently imprecise as to be statistically indistinguishable from the trend estimated among whites. It is also worth noting that the difference in subjective well-being for black men and women in 1972 is very different from that seen for whites-black women in 1972 were less happy than black men, while white women were happier than white men.

Given the findings among African-Americans, we should expect that the downward trend in female happiness will be larger when we examine trends among whites. Columns 3 and 4 report the results from running the regressions for whites only, initially with no controls (column 3), and then with a full set of controls interacted with gender (in column 4). Excluding blacks has a small amplifying affect on the coefficients and the decrease in happiness for women relative to men is slightly larger than our whole-population estimates in Table 1.

Given these racial differences, it is worth exploring whether there are compositional shifts among whites that might be impacting our finding of declining female happiness. In particular, the Hispanic population as a proportion of the total US population has tripled over our sample period. ${ }^{16}$ Unfortunately, it is not possible to control for Hispanic origin throughout the entire sample as the GSS began to collect information on Hispanic ethnicity in 2000. However, in each year, approximately $80 \%$ of the sample identified the country from which their ancestors came. As such, we construct a subsample of those who identify as white and selected a non-Spanish-speaking country as their heritage.

\footnotetext{
15 The GSS classifies race into "white", "black", and "other". A separate analysis of the "other" category yields results that are statistically significantly indistinguishable from those for whites. However, the small sample size yields estimates that are not precisely estimated and therefore not particularly informative.
} 
Our results for this group of white, non-Hispanics, shown in Columns 5 and 6 of Table 2, are very close to those for all whites. In further checks of potential shifts in the composition of whites, we limit the sample to whites who hail from individual European countries and find similar results for each group.

In Table 3, we turn to further disaggregating the trends among whites by age, employment, marital status, fertility and education. If there are particular changes in men's and women's lives that explain the decline in subjective well-being for women, then one might expect to see differences based on the time period in life that we examine. For example, if female unhappiness is rising due to the extra pressures of combining home and market work then one would suspect that the decline in female happiness would be particularly large among women in their peak child-rearing years or among women with young children in the home.

Before describing these results, it is worth emphasizing the tremendous changes in the composition of these groups. In 1970 less than a quarter of the adult population had attended college and only $10 \%$ had a bachelor's degree. By 2005 , over $50 \%$ had attended college and half of those had achieved a bachelor's degree. Moreover, this change was not gender-neutral, as there has been a large scale increase in female educational attainment both absolutely, and relative to that of men, with female college attendance rates exceeding those of men for cohorts born in 1960 or later (Goldin, Katz, \& Kuziemko, 2006). Female labor force participation rates also rose dramatically from 43\% in 1970 to $59 \%$ in 2005, while male labor force participation fell from $80 \%$ to $73 \%$. Marital behavior has changed substantially, with a greater percent of the population having experienced divorce and remarriage (Stevenson and Wolfers 2007) and the married population has shift toward those who are more educated and older (Isen \& Stevenson, 2008). Finally, even the composition of people at various ages is shifting as life expectancy has increased. Because happiness can be considered both a trait of the individual as well as a reaction to the individual's life circumstance, this shifting of people into different categories confounds their underlying tendency toward happiness with changes in the hedonic experience of people in the group. While we endeavor to examine differences in the trends in happiness across groups we want to emphasize the difficulty in interpretation as compositional shifts may result in trends over time that reflect changing selection. Even a finding of no difference between groups may be masking changes in the hedonic experience of various groups if the changes resulting from compositional shifts go in the opposite direction as the changing hedonic experience.

\footnotetext{
16 The US went from $4.7 \%$ in 1970 to an estimated $15.5 \%$ in 2010 . For more information see the Census presentation "Hispanics in the United States" located at: http://www.census.gov/population/www/socdemo/hispanic/files/Internet_Hispanic in_US_2006.pdf
} 
Turning to examining happiness by age group, the first three columns of Panel A show the results of an ordered probit regression of happiness on female*(Year-1972)/100 and male*(Year1972/100) each interacted with four age categories. The trend toward lower subjective well-being for women, both absolutely and relative to men, is seen in every age category in roughly equal measure. The bottom row of the Panel reports the p-value from testing whether the coefficients in each age category are statistically significantly different from one another. The trends for women and the difference in the trends between women and men are not significantly different across the ages. Among men, there is a pattern of increasing happiness among the young and decreasing happiness among those ages 45-59.

Columns 4-6 add controls for life outcomes with the same caveats about the difficulty of interpreting results with controls as discussed previously. As in Table 1, controls are added for employment, income, marital status, education outcomes, number of children ever born, parent's education, religion, and region separately for men and women. Examining the trends holding these life outcomes constant we see that the trends in happiness have favored the young over the old for both men and women. The decline in female happiness is largest among those over age 60, while the happiness of young men has trended upward compared with flat trends for older men. While these trends are statistically significantly different across the age groups, these differences across age are similar for men and women and thus the differences between the female and male trends are not statistically significantly different from one another. Thus, trends in the gender happiness gap by age offer no evidence of particularly large declines for prime age women (or any other group of women) relative to that of men. Moreover, even though happiness rises unconditionally with age, controlling for the aging of the population has no impact on the estimated trends.

In addition to breaking the results down by age we investigated the possibility of cohort specific trends, analyzing trends separately for decadal birth cohorts from the 1910s through the 1960s. This exercise yielded similar declines in the relative well-being of women across these cohorts. Adding controls-and particularly controls for age-complicates things, due to the wellknown collinearity of age, cohort and time. Our case is slightly different, in that we are interested in the interactions of time with gender; consequently we can break this collinearity by assuming that happiness varies by age in a stable way over time that is the same for both genders, allowing us to estimate separate cohort and time effects, by gender. Again, we find similar declines in the gender happiness gap across all cohorts. Thus there is no evidence that women who experienced the protests and enthusiasm of the women's movement in the 1970s have seen their happiness gap widen by more 
than for those women who were just being born during that period. This finding provides suggestive evidence that the decline in happiness cannot be explained by the peaking optimism of those participating in the women's movement in the 1970s.

If the burdens of entering the workforce are playing a role in declining female happiness then perhaps the decline in happiness will be concentrated among women who are employed. Panel B shows the results of an ordered probit of happiness on female*(Year-1972/100) and male*(Year1972/100) each interacted with two employment status variables. This regression shows that both women who are employed and those who are not have experienced roughly similar declines in subjective well-being in both the main specification shown in Column 1 and when controls are added in Column 4. Similarly, there are no differences by employment in the trend for males or the difference between women and men in the trends. There have been large compositional shifts in employment for women, but there are neither trend nor level differences (results not shown) in happiness by employment for women throughout the 35 year period.

Panels C and D of Table 3 disaggregate our data by marital status and fertility outcomes. While the proportion in the sample who are married fell by a third over the course of our sample, and married people typically report being happier than unmarried people, this compositional change does not explain the decline in female happiness. Panel $\mathrm{C}$ shows no significant differences in the happiness trends by marital status for women or men or the difference between the two. Table 1 showed that adding controls for life outcomes-including marriage-yield similar trends in happiness. One possible explanation for why this compositional shift has little impact on the trends in happiness is simply that the causal impact of marriage on happiness is much smaller than that which is observed in the cross-section due to selection into marriage on happiness traits.

A common suspect for the source of women's declining happiness is the burden of balancing children and a career. In Panel D, we first run regressions for the total population, in which we estimate female and male time trends separately for those with and without children. There are no statistically significant differences in the trends for women with and without children nor are their differences between these groups in the trend in happiness for men (or the subsequent trend in the happiness gap). Along with the decline in marriage has come a rise in single parenthood, both through growth in out-of-wedlock births and through divorce. ${ }^{17}$ Thus, we disaggregate the fertility results to

\footnotetext{
${ }^{17}$ Equally, divorce began declining in 1979 and the proportion of children involved per divorce also begins to decline in the 1980s.
} 
consider trends in happiness separately among single parents and married parents, and, to account for the duel burden of working parents, between employed parents and non-employed parents. Once again, we see similar trends in happiness across these groups, casting doubt on the hypothesis that trends in marriage and divorce, single parenthood, or work-family balance are at the root of the happiness declines among women. Although, it bears reminding that compositional shifts in all of these groups may hinder identifying the true hedonic shifts that may have occurred due to societal changes in family behavior.

Finally, we turn to examining differential trends in happiness across education groups. Education has been rising throughout the period and higher education is associated with greater happiness. Moreover, rising inequality has led to higher incomes for those with more education, while the wages of men with less education have fallen or been stagnant for much of this period. Trends in male happiness mirror these trends in male earnings - men with a college degree or more have become happier over time, while men with a high school degree or less have become less happy over time. The patterns for women however are not similar: women of all education groups have become less happy over time with declines in happiness having been steepest among those with some college. Examining the differences in the trends between women and men, declines are seen for all groups; however, as with the absolute decline in women's happiness, the relative decline is largest among those with some college. If, however, we condition on life outcomes, the differences in the trends by age group for both women and men are less pronounced.

Before concluding that women with some college have experienced particularly large declines in subjective well-being, it is again worth emphasizing the changed composition of the education category. Both men and women have had increasing educational attainment over this period, however those changes have been most pronounced for women. In particular, few women had degrees beyond high school in the 1970s and the number of those continuing on to college has risen enormously, both absolutely and relative to that of men. Thus, changing selection into higher levels of education likely contributes to the differential happiness trends by educational attainment. Since the differences in the trends by education may partly, or wholly, reflect the differential changes in which women and men select into higher education, we re-analyze these data, grouping individuals instead by their father's level of education (a rough measure of socioeconomic status). While there is likely changing selection of fathers into education through time, this differential selection is likely similar for fathers of daughters and fathers of sons. These results suggest that the trend in the gender happiness gap is roughly similar across the socioeconomic spectrum. 
All told, these data suggest that both the absolute decline in happiness among U.S. women, and the even larger decline relative to men, appears pervasive and is evident irrespective of the age, marital, labor market, or fertility status of the group analyzed. As such these data provide little evidence for any of the mechanisms discussed in the introduction to be driving the decline in women's happiness.

We now turn to examining trends across a number of European countries. Happiness in Europe, unlike that in the United States, has been increasing along with rising GDP. Despite this difference in overall happiness trends we find a similar pattern of relative declines in women's happiness in Europe. Our main international data source is the Eurobarometer, a series of repeated cross-sections, designed to gauge trends within member states of the European Union. The Eurobarometer began asking about life satisfaction in a core of 9 countries in 1973 and expanded to 12 countries by 1985 (including Northern Ireland), and included 17 countries (counting East and West Germany separately) by the end of our sample (we are analyzing the Mannheim Eurobarometer Trend File, 1970-2002). ${ }^{18}$ For most countries, a cross-section of roughly 1,000 people is interviewed in each biannual survey round (turning to quarterly in 2000). There are two key questions measuring an individual's subjective well-being. The first asks about life satisfaction-“On the whole, are you very satisfied, fairly satisfied, not very satisfied or not at all satisfied with the life you lead?", while the second question asks more directly about happiness-“Taking all things together, how would you say things are these days-would you say you're very happy, fairly happy, or not too happy these days?". The life satisfaction question is available for a longer period-it was asked every year from 1973 to 1998, except 1974 and 1996, while the happiness question was asked only from 1975 to 1986 (and not in 1980 or 1981). While life satisfaction and happiness are somewhat different concepts, responses are highly correlated.

Figure 4 shows trends in life satisfaction by gender, aggregating across the European Union. As in the U.S., women's well-being was higher than men's in the early 1970s, but by the early 2000s, women were somewhat less well off. As with U.S. women, the well-being of European women has declined relative to men. However, while U.S. women also experienced an absolute decline in wellbeing, the subjective well-being of European women has risen in an absolute sense. In the first row of Table 4, we formalize these comparisons, finding that the magnitude of the difference between the female and male trends-the closure of the gender happiness gap-is both statistically significant and

\footnotetext{
${ }^{18}$ Country samples are weighted to be representative of the entire EU.
} 
remarkably similar to that for the United States. The last three columns report on these trends when conditioning on a rich set of controls (including age, nation, employment status, marital status, and education, all interacted with gender), and yield findings that are similar to the raw trends. ${ }^{19}$ The sparser data asking about happiness are analyzed in the second row, and suggest a similar pattern, albeit a somewhat larger decline in the happiness of women relative to men.

The remainder of Table 4 estimates trends in subjective well-being separately by country. In order to maintain reasonable sample sizes, we focus only on life satisfaction, and only on those countries entering the data before the 1990s. These results suggest that the trend rise in well-being across Europe is fairly widespread, and the well-being of men rose in all countries with the exceptions of a small (and insignificant) decline in Greece and a larger decline in Belgium. The increase in wellbeing in many of these countries is remarkable, and Italy experienced particularly large increases. In most of these countries, women's life satisfaction has also grown.

However, these increases in subjective well-being have been experienced to a greater degree by men, leading to a pervasive decline in well-being among women relative to men. Indeed, women's happiness fell relative to men's in all but one of the countries in the sample, and while the pattern is by no means uniform, the magnitudes are remarkably similar. The only exception to this rule is West Germany, although even there, the data are not clear cut. ${ }^{20}$

We have also examined alternative data sources on the evolution of happiness in other industrialized nations, but either the infrequency or small country sample sizes in data collected by the International Social Survey Program and the World Values Study make them ill-suited for assessing whether the gender happiness gap is changing. To see this, note that using annual GSS data for the U.S. yielded an estimate of the change in the gender happiness gap over a 35-year period that was $1 \frac{1}{2}$ times the standard deviation of annual measures of the gender happiness gap.

Thus, while the magnitude of trend in the gender happiness gap could be reliably discerned from idiosyncratic year-to-year changes in data collections running for many years (like the GSS or the Eurobarometer), these alternative cross-national data cover shorter periods (over which less change occurred), involve fewer observations, and involve greater noise due to changes in survey design

\footnotetext{
${ }^{19}$ It should be noted that the set of control variables available in these data are not quite as rich as those available in the GSS.

${ }^{20}$ Referring instead to the GSOEP (a German panel dataset that has run since 1984), we find parallel declines in life satisfaction for both men and women in West Germany, and hence no trend in the gender happiness gap.
} 
between waves, ultimately undermining the ability of these data to falsify most interesting hypotheses. And indeed, this is what we find: our key estimates for the U.S. and Europe (shown in Table 1and Error! Reference source not found.) suggest a trend in the gender well-being gap of about $0.3 / 100$ per year, and this lies in the 95\% confidence interval of 125 of the 147 country-survey estimates of the differential trend that we examine. The confidence intervals around these countryspecific estimates are extremely wide-typically 5-10 times those from either the GSS or Eurobarometer estimates.

\section{Satisfaction in Various Life Domains}

In aggregate women's subjective well-being has declined relative to that of men, but with which aspects of their lives are they now less satisfied? In this section we explore a number of survey questions that assess men's and women's satisfaction across a number of domains: their work, their financial lives, their family, and their health.

We begin by analyzing job satisfaction, motivated by the observation that many laud the women's movement for having improved their employment options. ${ }^{21}$ Research in social psychology and labor economics has long highlighted the "paradox of the contented female worker" (Crosby, 1982). The paradox is simply that despite women being over-represented in jobs that are worse by many objective standards-they face lower wages, occupational segregation into jobs with lower pay and fewer opportunities for advancement-they have historically reported higher levels of job satisfaction than men. One possible explanation is that women who would get the least satisfaction from market work have been more likely to select home production. A particular advantage of job satisfaction data from the General Social Survey is that they ask both homemakers and the employed: "On the whole, how satisfied are you with the work you do? Would you say you are very satisfied, moderately satisfied, a little dissatisfied, or very dissatisfied?" The trends in the gender job satisfaction gap are shown in Panel A of Table 5. The first row shows trends in job satisfaction for men and women and there is no discernable trend for either men or women over the period (and hence no

\footnotetext{
${ }^{21}$ In an open-ended question from the 1999 Virginia Slims American Women's Opinion Poll respondents were asked "What do you think are the key accomplishments of the women's movement". More women nominated improved employment opportunities than any other category: overall $17 \%$ of women nominated "employment opportunities/better jobs available to women", 7\% noted "women are now accepted in the work-force"; $6 \%$ noted "equal paying jobs"; $6 \%$ noted "equal jobs"; 5\% noted "better paying jobs"; $2 \%$ noted "less discrimination"; and in broader categories, $14 \%$ suggested "equal rights/equal opportunities"; and 10\% pointed to "more freedom/freedom to make choices".
} 
differential trend). Examining differences in levels we found little difference in the mean job satisfaction of men and women.

Subsequent regressions disaggregate these data so as to disentangle job satisfaction among those engaged in market versus non-market work; these comparisons reflect both the changing hedonic experience of work for men and women, and large changes in the selection of women into market-based employment through this period. Trends in job satisfaction among women and men engaged in market work have remained roughly constant, although the point estimates suggest a decline in satisfaction among women. Throughout the period women "keeping house" report lower job satisfaction compared with women who are employed in the market. Examining the trends over time, we see that the job satisfaction of women "keeping house" has risen and thus closed some of the job satisfaction gap between women engaged in market work and women engaged in home production..$^{22}$ Compositional shifts can potentially explain both the rise in job satisfaction among homemakers and a decline in job satisfaction with market work; this would occur, for example, if the women most likely to shift from home-making to the market have lower job satisfaction with homemaking compared to the median homemaker and lower job satisfaction than the median women working in the labor market. All told, job satisfaction can do little to explain the overall happiness patterns observed as women, unconditional on their choice of market versus home production, remain similarly satisfied with their work both when compared with the past, and when compared with men.

As women have entered the labor force they have also increased their role in managing household finances, leading us to explore the GSS question asking: "We are interested in how people are getting along financially these days in Panel B. So far as you and your family are concerned, would you say that you are pretty well satisfied with your present financial situation, more or less satisfied, or not satisfied at all?" Women begin the sample with reported financial satisfaction that is similar to that seen for men and men's satisfaction shows no obvious trend. In contrast, women's financial satisfaction declines through the sample and, by the end of the sample, they are substantially less satisfied with their household financial situation than are men. Women's decline in financial satisfaction and the decline relative to that of men are similar in the baseline specification and when controlling for life outcomes including family income (interacted with gender). However, in the full

\footnotetext{
22 While the job satisfaction of men keeping house has risen substantially, this difference is not worth emphasizing as only around $1 \%$ of men are homemakers - compared with $30 \%$ of women-and the size of this group has tripled from about $1 / 2 \%$ to $1 \frac{1 / 2}{2} \%$ of men since 1970 suggesting large compositional shifts.
} 
controls specification we also see a decline in the financial satisfaction of men, albeit a decline that is smaller than that seen among women.

Because the survey question asks about a family's financial situation, it is useful to assess whether these trends reflect the different subjective responses of men and women to their combined family circumstances, or different satisfaction of female- and male-headed households. Thus, we disaggregate by marital status. Here we find that while married women, unconditionally, have become more satisfied with their family's financial situation, married men have become even more satisfied and the relative decline in financial satisfaction is similar to that seen for the entire sample. Adding controls leads to a finding of steeper declines in financial satisfaction among married women as well as declines among men. Among those not married, in both the baseline and full controls specifications we see that both men and women have become less satisfied, but again, women have become even less satisfied with their financial relative to the trends for men and the differential gap remains negative.

Financial satisfaction is correlated with happiness for both men and women-with a correlation between the two of 0.3 for both. And the magnitude of the decline in women's satisfaction with their financial situation is similar to the decline in women's happiness overall. However, the relative declines in financial satisfaction are not sufficient to explain the decline in women's happiness. To assess the potential role for declining financial satisfaction in the overall decline in the happiness of women, we include the subjective assessments of financial satisfaction as controls in our earlier regressions. Specifically, we re-ran equation [1], but included as further controls financial satisfaction interacted with gender. This regression (not shown) reveals that financial satisfaction is an important contributor to both men and women's happiness; however it only dampens the absolute decline in female happiness slightly and yields no change in the relative decline (as controlling for financial satisfaction contributes to a positive male trend in happiness). Thus, while declining financial satisfaction is clearly contributing to women's declining happiness, this alone cannot account for the overall decline in women's happiness both absolutely and relative to that of men.

Turning to marital satisfaction in Panel C, we analyze trends in answers to the question "Taking things all together, how would you describe your marriage? Would you say that your marriage is very happy, pretty happy, or not too happy?" Naturally this question is only asked of married people, so it is worth re-emphasizing our earlier finding that the overall relative decline in women's happiness was common across both the married and unmarried populations. On average, women are less happy with their marriage than men and women have become less happy with their marriage over time. However, 
men have also become less happy with their marriage over time and thus, the gender gap in marital happiness has been largely stable over time.

It is still possible that declines in marital satisfaction have contributed differentially to men's and women's happiness. Examining the correlation between happiness and marital happiness we find that marital happiness is more closely linked to happiness for women. The correlation between overall happiness and marital happiness is 0.4 for married men and 0.5 for married women. It should be noted that it is difficult to assess the role of changes in marital satisfaction on women's overall happiness since marital satisfaction is only asked among those who are married and changing selection over time in this group makes causal inference challenging. However, as with financial satisfaction, we attempt to examine the possible role that marital happiness is playing in the declining happiness among married women relative to married men by including controls for marital happiness interacted with gender in the specification from Table 1. We find that the relative decline between women's and men's happiness is similar in magnitude (with a point estimate that is somewhat larger) once controls for marital happiness is taken into account.

Finally, in Panel D, we examine women's and men's subjective assessment of their health. When asked to rate their health on a four point scale from poor to excellent, women throughout the period report lower health satisfaction than do men. However, Table 5 shows that women's assessment of their health over this period-a period during which the women's movement led to an increase focus on women's specific health needs has increased. ${ }^{23}$ In contrast men's subjective health assessment has not changed much over this period. As a result, women are reporting greater health over the period both absolutely and relative to men. By the end of the sample, the subjective health "gap" between men and women has nearly closed. With controls for life outcomes added, the trend in women's reported health changes sign and is declining over this period.

In order to try to assess whether the combination of these measures of domain-specific satisfaction can account for the overall decline in the relative happiness of women, we included these subjective assessments of job, marital, financial and health satisfaction as controls simultaneously in our earlier regressions. As done for each of the domains individually, we start with equation [1] and

\footnotetext{
${ }^{23}$ The Boston Women's Health Book Collective published the first edition of Our Bodies, Ourselves in 1973 and launched a movement encouraging women to have a say in their own healthcare and a focus on women-specific healthcare issues. This movement grew in the ensuing decades and led to increased research and understanding of conditions affecting women exclusively or differently than men.
} 
add a saturated set of dummy variables describing each of these four satisfaction measures, interacting each with gender, to allow for different effects by gender. Because of the way these variables were collected, this required us to analyze a sample of married men and women who were either working or keeping house. Missing values in various domain-specific data also meant dropping four years from the sample. While these estimates are not intended to reflect a causal model of happiness, they provide a useful accounting device. These control variables all had the expected signs, with greater satisfaction in any domain yielding greater overall happiness. But overall, the residual (or unexplained) trend in the relative happiness of women is even more negative.

From 1976-1994, the General Social Survey also included a battery of questions asking how much satisfaction respondents get from a range of areas. Analysis of these data are shown in Table 6. These regressions show that friends and hobbies have become more important sources of satisfaction for women over time, both absolutely and relative to men. However, the nature of the question makes this finding difficult to interpret, as the increase in satisfaction that women derive from friends may imply greater satisfaction with that domain, or differences in how men and women have come to see friends as a source of life satisfaction. Indeed, one limitation of the GSS data is that we have no way of assessing whether the importance of specific domains to overall happiness has changed over time.

We now turn to the Monitoring the Future survey, which probes subjective well-being in far greater detail than any other study run during our sample period. The obvious limitation with these data is that the important dimensions of well-being for $12^{\text {th }}$ graders may be very different from those for adults. Nonetheless, the relative decline in the subjective well-being of $12^{\text {th }}$ grade girls appeared as strongly as in our adult samples and a greater understanding of changes in the well-being of these girls may shed light on the overall paradox. The data contain two useful sets of questions that allow us to assess both the changing contribution of specific areas of these teenagers lives to well-being and their changing satisfaction in specific areas.

We first explore the satisfaction of youth with various aspects of their lives. As before, we use ordered probit regressions to estimate trends in these variables, and Figure 5 shows these trends by gender, and in the leftmost panel, the trend in female relative to male well-being. Two of these questions are rather global in nature, asking about satisfaction with "yourself", or with "your life as a whole these days". These results largely parallel the response to the happiness question analyzed in the previous section, with the subjective well-being of girls falling and the well-being of boys rising. Turning to the more specific questions, the common thread appears to be that $12^{\text {th }}$ grade girls increasingly find themselves to be under time pressure, with both absolute and relative declines in 
reported satisfaction with "time for doing the things you want", "the way you spend your leisure time", and "the amount of fun you are having". Interestingly, there is also a substantial decline in the proportion of these young women reporting satisfaction with "friends and people you spend time with". Because the trends for $12^{\text {th }}$ grade boys are typically to the right of those for girls-either less negative or even positive-girls have lost ground both absolutely and relative to that of boys.

We next turn to a battery of questions that measure the perceived importance of various aspects of their lives, as what may be changing are the weights given to various domains in determining global well-being. In Figure 6 we show the trends for young women and men in selfreports of the importance attached to various life domains. The most striking point is that young women are increasingly attaching greater importance to thirteen of the fourteen domains examined, with "finding purpose and meaning in my life" the only exception. An intensification of importance in many domains has also occurred among young men, albeit to a lesser extent. In terms of the differences in these trends by gender, young women have had an even greater intensification in most areas. In particular, there appears to be increasing ambition of young women beyond the domestic sphere, with greater importance attached to "being successful in my line of work", "being able to find steady work", "making a contribution to society", and "being a leader in my community". These data arguably suggest that women's life satisfaction may have become more complicated as the women have increased the number of domains in which they wish to succeed. Moreover, these data point to rising pressures beyond the much-discussed work-family tradeoff.

Although the analysis in this section is necessarily limited by available data, a few rough conclusions suggest themselves. Female subjective well-being is decreasing in many domains, however these decreases are in many cases similar to those experienced by men and there are few occurrences of a large or significant decrease in female subjective well-being relative to male wellbeing among the domains. Thus, it is difficult to pinpoint one aspect of women's lives that is contributing to their overall decrease in happiness relative to men. These data suggest an alternative framing of our research question: perhaps the puzzle is why men's happiness has not declined in line with women's happiness, given their observed decrease in well-being across a multitude of domains.

\section{Discussion}

By most objective measures the lives of women in the United States have improved dramatically over the past 35 years. Moreover, women believe that their lives are better; in recent 
polls asking about changes in the status of women over the past 25 or 50 years, around four in five adults state that the overall status of women in the U.S. has gotten better (and the remaining respondents break two-for-one towards "stayed the same" over "worse"). ${ }^{24}$ Additionally, the 1999 Virginia Slims Poll found that $72 \%$ of women believe that "women having more choices in society today gives women more opportunities to be happy" while only 39\% thought that having more choices "makes life more complicated for women." Finally, women today are more likely than men to believe that their opportunities to succeed exceed those of their parents.

Yet trends in self-reported subjective well-being indicate that happiness has shifted toward men and away from women. This shift holds across industrialized countries regardless of whether the aggregate trend in happiness for both genders is flat, rising, or falling: in all of these cases we see happiness rebalancing to reflect greater happiness for men relative to women. This finding of a decline in women's well-being relative to that of men raises questions about whether modern social constructs have made women worse off, or alternatively about the interpretability of subjective wellbeing data analyzed over long-time periods. Despite findings of higher well-being among women in countries with less gender discrimination (Bjørnskov, Dreher, \& Fischer, 2007), the decrease in gender discrimination since the 1970s has not improved the (subjectively perceived) lot of women. Rather than immediately inferring that the women's movement failed to improve the lot of women, we conclude with a simple taxonomy for organizing alternative explanations of this paradox.

First, there may be other important socio-economic forces that have made women worse off. A number of important macro trends have been documented-decreased social cohesion (Putnam, 2000), increased anxiety and neuroticism (Twenge, 2000), and increased household risk (Hacker, 2006). While each of these trends have impacted both men and women, it is possible for even apparently gender-neutral trends to have gender-biased impacts if men and women respond differently to these forces. For example, if women are more risk averse than men, then an increase in risk may lower women's utility relative to that of men.

The second possibility is that broad social shifts such as those brought on by the changing role of women in society fundamentally alter what measures of subjective well-being are capturing. Over time it is likely that women are aggregating satisfaction over an increasingly larger domain set. For example, life satisfaction may have previously meant "satisfaction at home" and has increasingly come

\footnotetext{
${ }^{24}$ Survey by CBS News, April 28-April 30, 2006; Survey by CBS News, May 20-May 24, 2005. Retrieved September 10, 2007 from the iPOLL Databank, The Roper Center for Public Opinion Research, University of Connecticut.
} 
to mean some combination of "satisfaction at home" and "satisfaction at work. This averaging over many domains may lead to falling average satisfaction if it is difficult to achieve the same degree of satisfaction in multiple domains. One piece of evidence along these lines is that the correlation between happiness and marital happiness is lower for women who work compared with those who are stay at home wives, and the correlation has fallen over time for all women in our sample. Unfortunately, data limitations prevent us from fully exploring this theory.

Subjective well-being data have come to be used in the psychology and economics literatures because they have been shown to be correlated with more objective measures of happiness. Yet these measures do not necessarily indicate that subjective well-being measures are able to capture the positive or negative consequences of large-scale social changes over time. It has been recognized that an individual's assessment of their well-being may reflect the social desirability of responses and Kahneman (1999) argues that people in good circumstances may be hedonically better off than people in worse circumstances, yet they may require more to declare themselves happy. In the context of the findings presented in this paper, women may now feel more comfortable being honest about their true happiness and have thus deflated their previously inflated responses. Or, as in Kahneman's example, the increased opportunities available to women may have increased what women require to declare themselves happy. And indeed, Figure 7 shows that contrary to the subjective well-being trends we document, female suicide rates have been falling, even as male suicide rates have remained roughly constant through most of our sample. As such, from the early 1970s to the mid-1990s the ratio of female-to-male suicide declined. It is plausible that the happiness of those at the extreme tail that is represented by suicide may have risen, while the happiness of those at the median may have fallen. Equally, this may indicate changing responses to the well-being question for a given level of happiness. In either case, the link between reported well-being (a subjective measure) and suicide (an objective measure) has changed over time.

Finally, the changes brought about through the women's movement may have decreased women's happiness. The increased opportunity to succeed in many dimensions may have led to an increased likelihood of believing that one's life is not measuring up. Similarly, women may now compare their lives to a broader group, including men, and find their lives more likely to come up short in this assessment. Or women may simply find the complexity and increased pressure in their modern lives to have come at the cost of happiness.

Diener (2000) notes that one of the hallmarks of subjective well-being is that it is subjective, stating that "objective conditions such as health, comfort, virtue, or wealth" are "notably absent" and, 
while influencing subjective well-being, "they are not seen as inherent". This aspect of subjective wellbeing makes understanding what is behind declining female happiness a challenging task, yet decoding the paradox identified in this paper may indeed be the key to a better understanding of subjective well-being. 


\section{References}

Aguiar, M., \& Hurst, E. (2007). Measuring Trends in Leisure: The Allocation of Time over Five Decades. Quarterly Journal of Economics , 122 (3), 969-1006.

Akerlof, G. A., Yellen, J. L., \& Katz, M. L. (1996). An Analysis of Out-of-Wedlock Childbearing in the United States. Quarterly Journal of Economics , CXI (2), 277-317.

Autor, D., Katz, L., \& Kearney, M. (2008). Trends in U.S. Wage Inequality:Re-Assessing the Revisionists. Review of Economics and Statistics , 90, 300-23.

Bjørnskov, C., Dreher, A., \& Fischer, J. A. (2007). On Gender Inequality and Life Satisfaction: Does Discrimination Matter? University of St. Gallen Department of Economics Working Paper Series , $2007-$ 07.

Blanchflower, D., \& Oswald, A. (2004). Well-Being Over Time in Britain and the USA. Journal of Public Economics , 88 (7-8), 1359-1386.

Blau, F. D. (1998). Trends in the Well-being of American Women. Journal of Economic Literature , 36 (1), 112-165.

Blau, F. D., \& Kahn, L. M. (2007). Changes in the Labor Supply Behavior of Married Women: 1980-2000. Journal of Labor Economics , 25 (3), 393-438.

Crosby, F. (1982). Relative Deprivation and Working Women. New York: Oxford University Press.

Deaton, A. (2008). Income, aging, health and well-being around the world: Evidence from the Gallup World Poll. Journal of Economic Perspectives , 22 (2), 53-72.

Diener, E. R. (2006). Beyond the Hedonic Treadmill: Revising the Adaptation Theory of Well-Being. American Pyschologist, 61 (4), 305-314.

Diener, E. (1984). Subjective Well-Being. Psychological Bulletin , 95 (3), 542-575.

Diener, E. (2000). Subjective well-being: The Science of Happiness and a Proposal for a National Index. American Psychologist, 55 (1), 34-43.

Easterlin, R. A. (1974). Does economic growth improve the human lot? Some empirical evidence. In P. A. David, \& M. W. Reder, Nations and Households in Economic Growth: Essays in Honor of Moses Abramowitz. New York: Academic Press, Inc.

Elwood, D. T., \& Jencks, C. (2001). The Spread of Single-Parent Families in the United States since 1960 . John F, Kennedy School of Government Working Paper, Harvard University . 
Goldin, C., \& Katz, L. (2007). Long-Run Changes in the Wage Structure: Narrowing, Widening, Polarizing. Brookings Papers on Economic Activity (2), 135-165.

Goldin, C., Katz, L., \& Kuziemko, I. (2006). The Homecoming of American College Women: The Reversal of the College Gender Gap. Journal of Economic Perspectives , 20 (4), 133-156.

Hacker, J. (2006). The Great Risk Shift: The Assault on American Jobs, Families, Health Care, and Retirement--And How You Can Fight Back. Oxford: Oxford University Press.

Hochschild, A., \& Machung, A. (1989). The Second Shift. New York: Viking.

Isen, A., \& Stevenson, B. (2008). Women's Education and Family Behavior: Trends in Marriage, Divorce and Fertility. University of Pennsylvania.

Kahneman, D. (1999). Objective Happiness. In D. Kahneman, E. Diener, \& N. Schwarz, Well-Being: The Foundations of Hedonic Psychology. New York: Russell Sage Foundation.

Kahneman, D., \& Krueger, A. B. (2006). Developments in the Measurement of Subjective Well-Being. Journal of Economic Perspectives , 20 (1), 3-24.

Kimball, M., \& Willis, R. (2006). Utility and Happiness. mimeo, University of Michigan .

Krueger, A. (2007). Are We Having More Fun Yet? Categorizing and Evaluating Changes in Time Allocation. Brookings Papers on Economic Activity , 2, 193-215.

Oswald, A. J., \& Powdthavee, N. (2007). Death and the Calculation of Hedonic Damages. University of Warwick.

Pezzini, S. (2005). The Effect of Women's Rights on Women's Welfare: Evidence From a Natural Experiment. The Economic Journal , 115, C208-C227.

Praag, B. v., \& Ferrer-i-Carbonell, A. (2008). Happiness Quantified: A Satisfaction Calculus Approach . Oxford University Press.

Putnam, R. D. (2000). Bowling Alone: The Collapse and Revival of American Community. New York: Simon \& Shuster.

Robinson, J., \& Godbey, G. (1999). Time for Life. University Park, PA: Pennsylvania State University Press.

Ross, C. E., \& Van Willigen, M. (1997). Education and the Subjective Quality of Life. Journal of Health and Social Behavior , 38 (3), 275-297.

Smith, T. W. (1990). Timely Artifacts: A Review of Measurement Variation in the 1972-1989 GSS. NORC, Univeristy of Chicago.

Stevenson, B., \& Wolfers, J. (2008, Spring). Economic Growth and Happiness: Reassessing the Easterlin Paradox. Brookings Papers on Economic Activity , 1-87. 
Stevenson, B., \& Wolfers, J. (2008). Happiness Inequality in the United. Journal of Legal Studies , 37 (S2), S33-S79.

Stevenson, B., \& Wolfers, J. (2007). Marriage and Divorce: Changes and Their Driving Forces. Journal of Economic Perspectives , 27-52.

Twenge, J. M. (2000). The Age of Anxiety? Birth Cohort Change in Anxiety and Neuroticism, 1952-1993. Journal of Personality and Social Psychology, 79 (6), 1007-1021.

U.S. Census Bureau. (2007). Historical Tables, Table A-5a. The Population 14 to 24 Years Old by High School Graduate Status, College Enrollment, Attainment, Sex, Race and HIspanic Origin: October 1976 to 0205. Retrieved September 9, 2007, from School Enrollment: http://www.census.gov/population/www/socdemo/school.html

Wolfers, J. (2003). Is Business Cycle Volatility Costly? Evidence from Surveys of Subjective Well-being. International Finance, 6 (1), 1-26.

Wolfers, J. (2006). Reassessing the Growth-Happiness Nexus. Conference Presentation, University of Pennsylvania, The Wharton School, USC Economics of Happiness Symposium. 

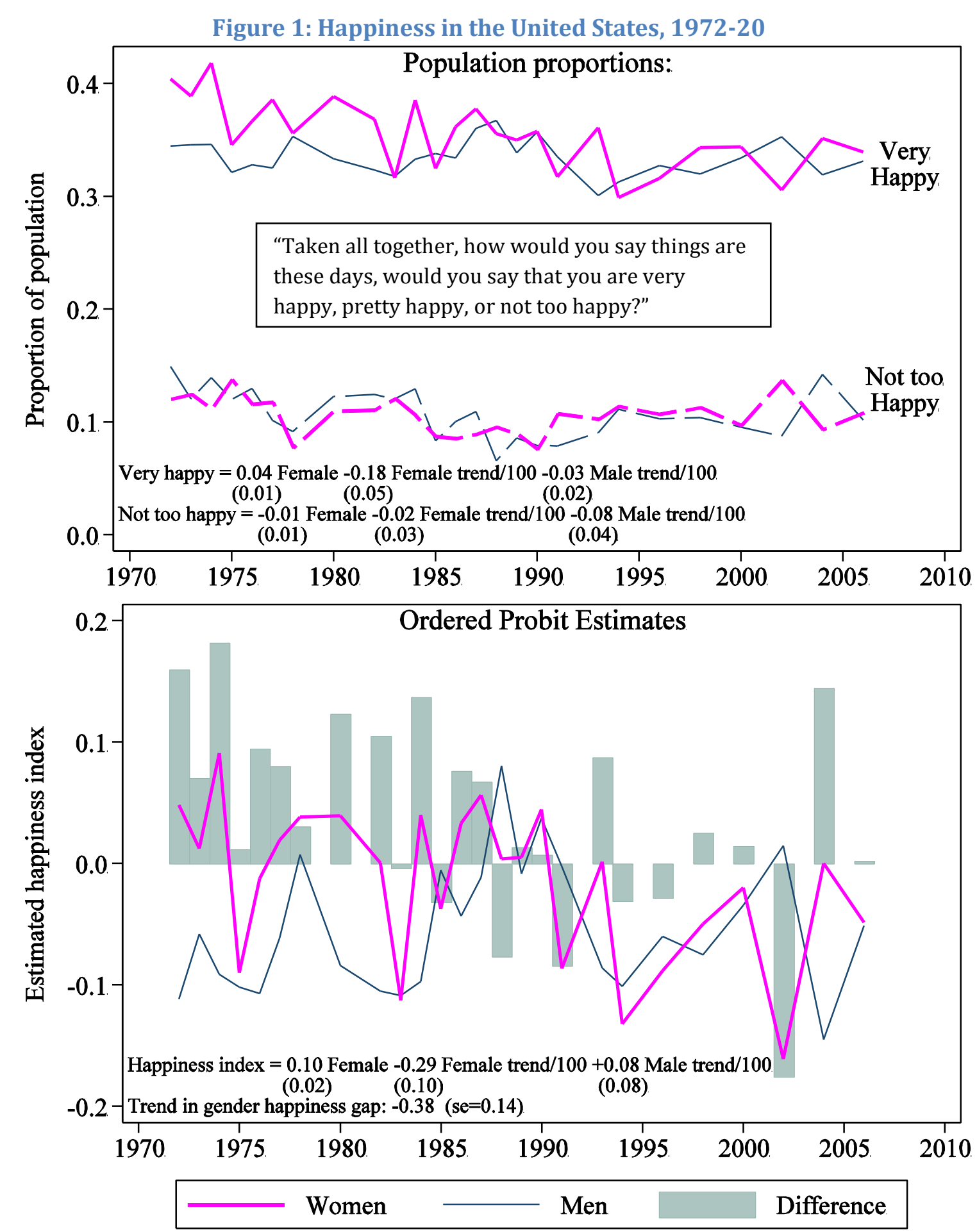

Source: General Social Survey, 1972-2006.

Notes: Top panel shows raw sample proportions for those who are "very happy" and "not too happy". The middle category, "pretty happy", is omitted. Bottom panel represents estimates from an ordered probit regression of happiness on a full set of survey*gender fixed effects; bars show the estimated gender well-being gap (female-male) in each survey round. The regression reported at the bottom estimates the trend in happiness over the period for men and women, illustrating that the decline in female happiness has been statistically significant while there has been little change in male happiness. 
Figure 2: Life Satisfaction in the United States, Virginia Slims Poll

In general, how satisfied would you say you personally are with your life today?

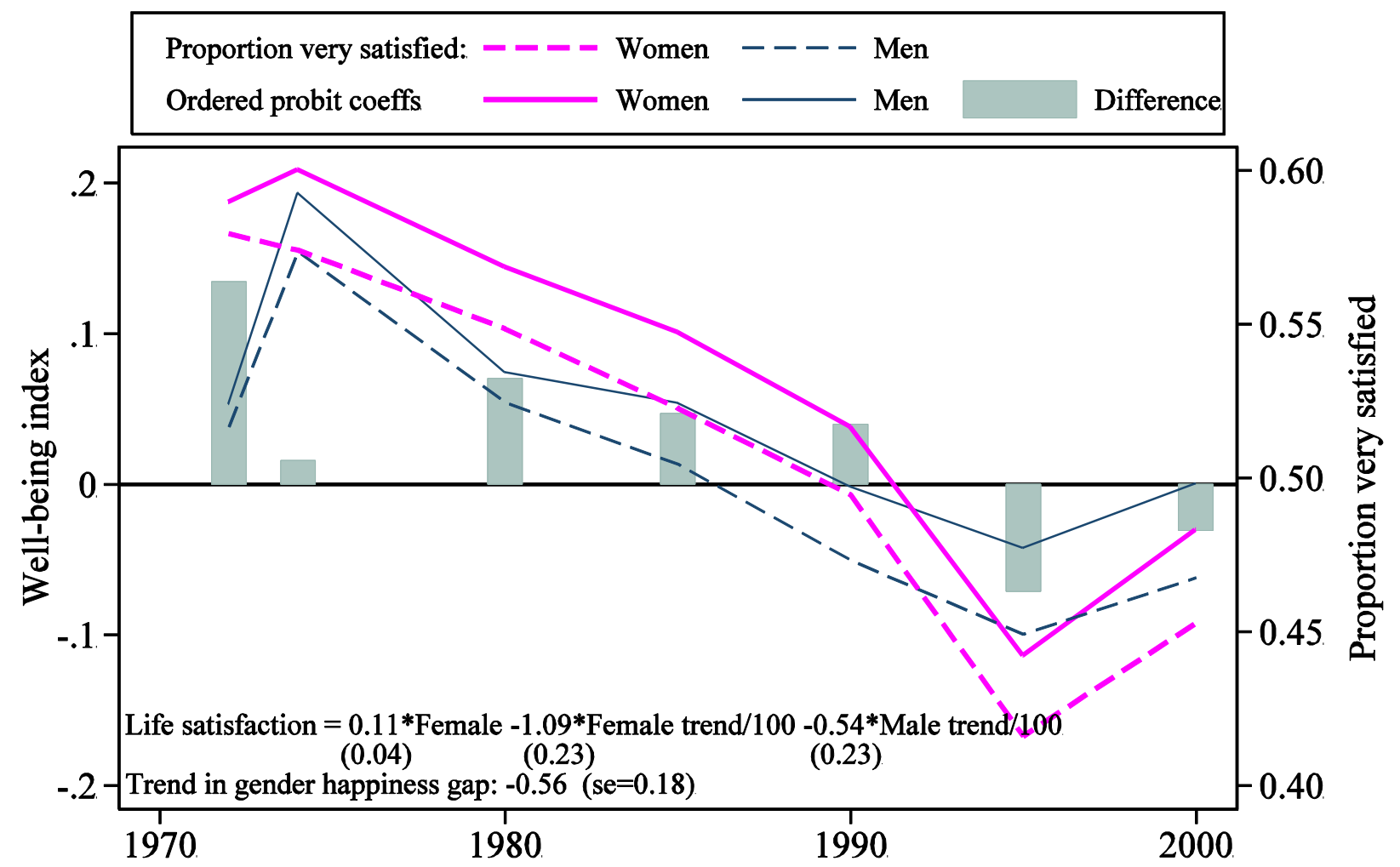

Source: Virginia Slims Survey of American Women (includes men), 1972, 1974, 1980, 1985, 1990, 1995 and 2000 (conducted by Harris and Associates in 1972 and The Roper Organization in 1974, 1980, 1985, 1990, 1995 and 2000).

Notes: Dashed lines show the proportion of the population reporting that they are very satisfed with their lives (right axis). Solid lines represent estimates from an ordered probit regression of life satisfaction on a full set of survey*gender fixed effects (left axis); bars show the estimated gender well-being gap (female-male) in each survey round. The regression reported at the bottom estimates the trend in happiness over the period for men and women, while the difference in the female and male trends is reported below the regression; standard errors are clustered by year. 
Figure 3: Happiness Among U.S. 12 ${ }^{\text {th }}$ Graders, 1976-2005

Taking all things together, how would you say things are these days?

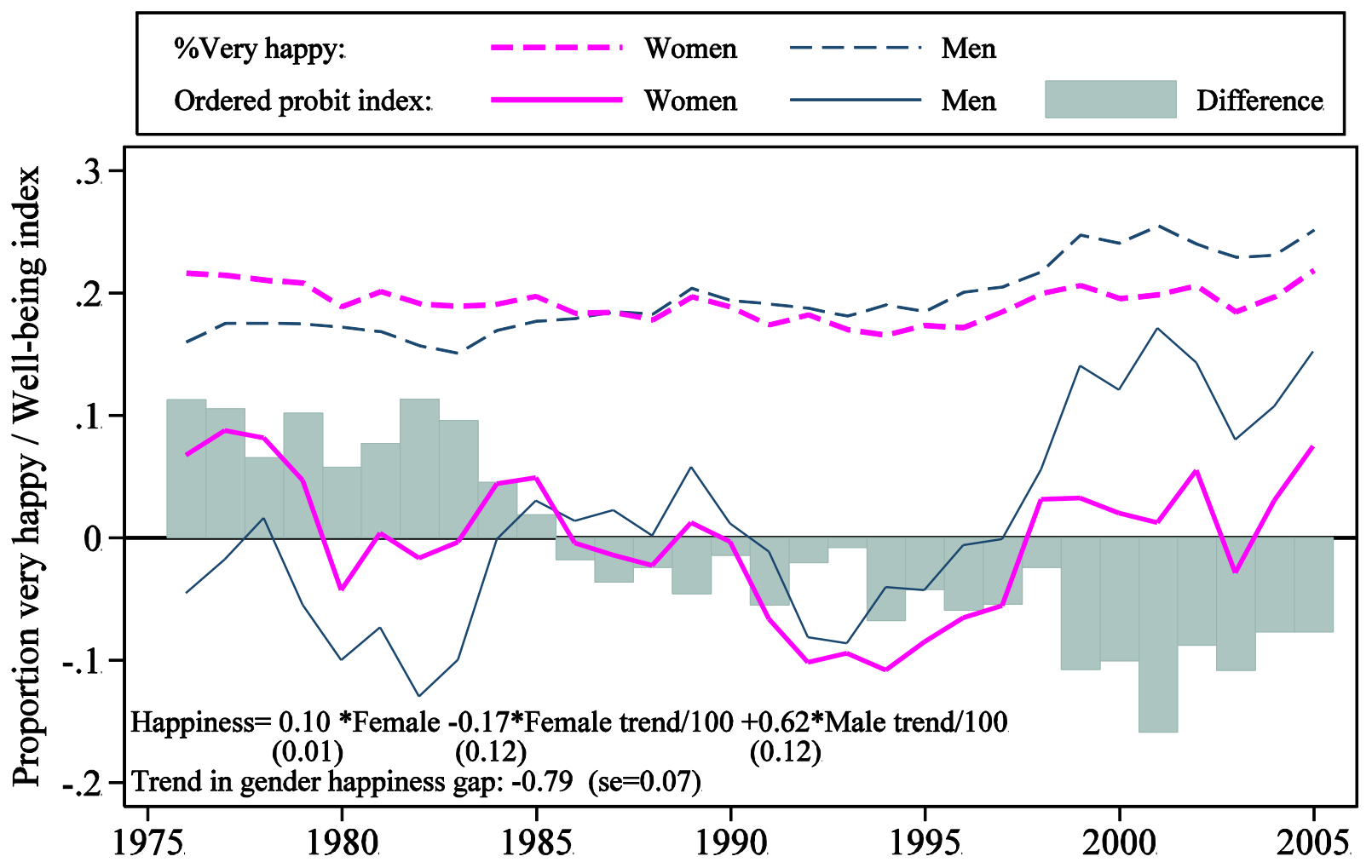

Source: Monitoring the Future 12th grade study, conducted annually from 1976 to 2005, by the Survey Research Center in the Institute for Social Research at the University of Michigan.

Notes: Dashed lines show the proportion of the population reporting that they are very satisfied with their lives. Solid lines represent estimates from an ordered probit regression of life satisfaction on a full set of survey*gender fixed effects; bars show the estimated gender well-being gap (female-male) in each survey round. The regression reported at the bottom estimates the trend in happiness over the period for men and women, while the difference in the female and male trends is reported below the regression. 


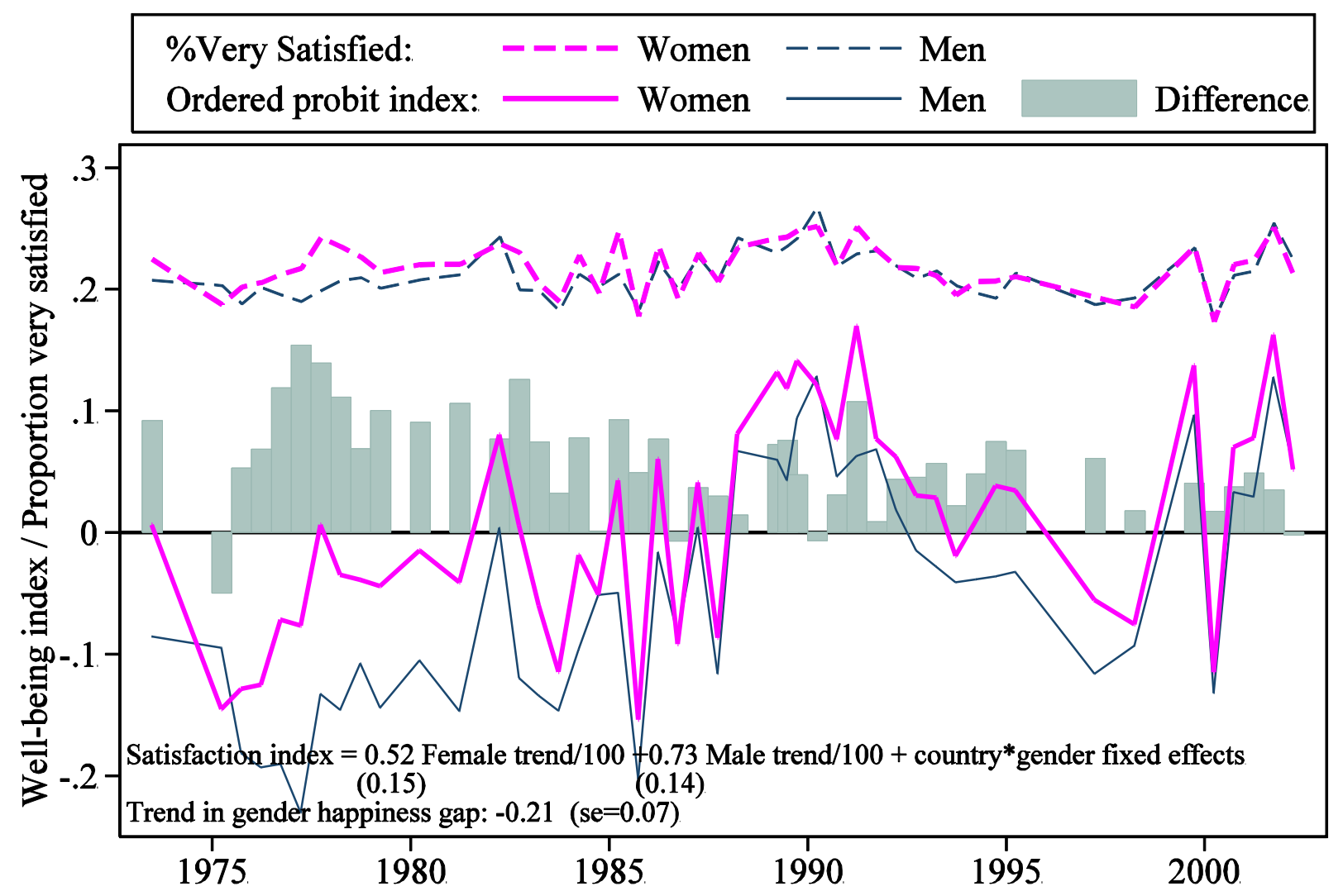

Source: Eurobarometer Trendfile (for 1973-2002); biannual Eurobarometer reports (for 2002-07)

Notes: Dashed lines show the proportion of the population reporting that they are very satisfied with their lives. Solid lines represent estimates from an ordered probit regression of life satisfaction on a full set of survey*gender fixed effects controlling for country*gender fixed effects; bars show the estimated gender wellbeing gap (female-male) in each survey round. Observations are weightd to be representative of the entire EU. The regression reported at the bottom estimates the trend in happiness over the period for men and women, while the difference in the female and male trends is reported below the regression. 
Figure 5: Trends in Well-being by Source, U.S. 12th Graders, 1976-2005

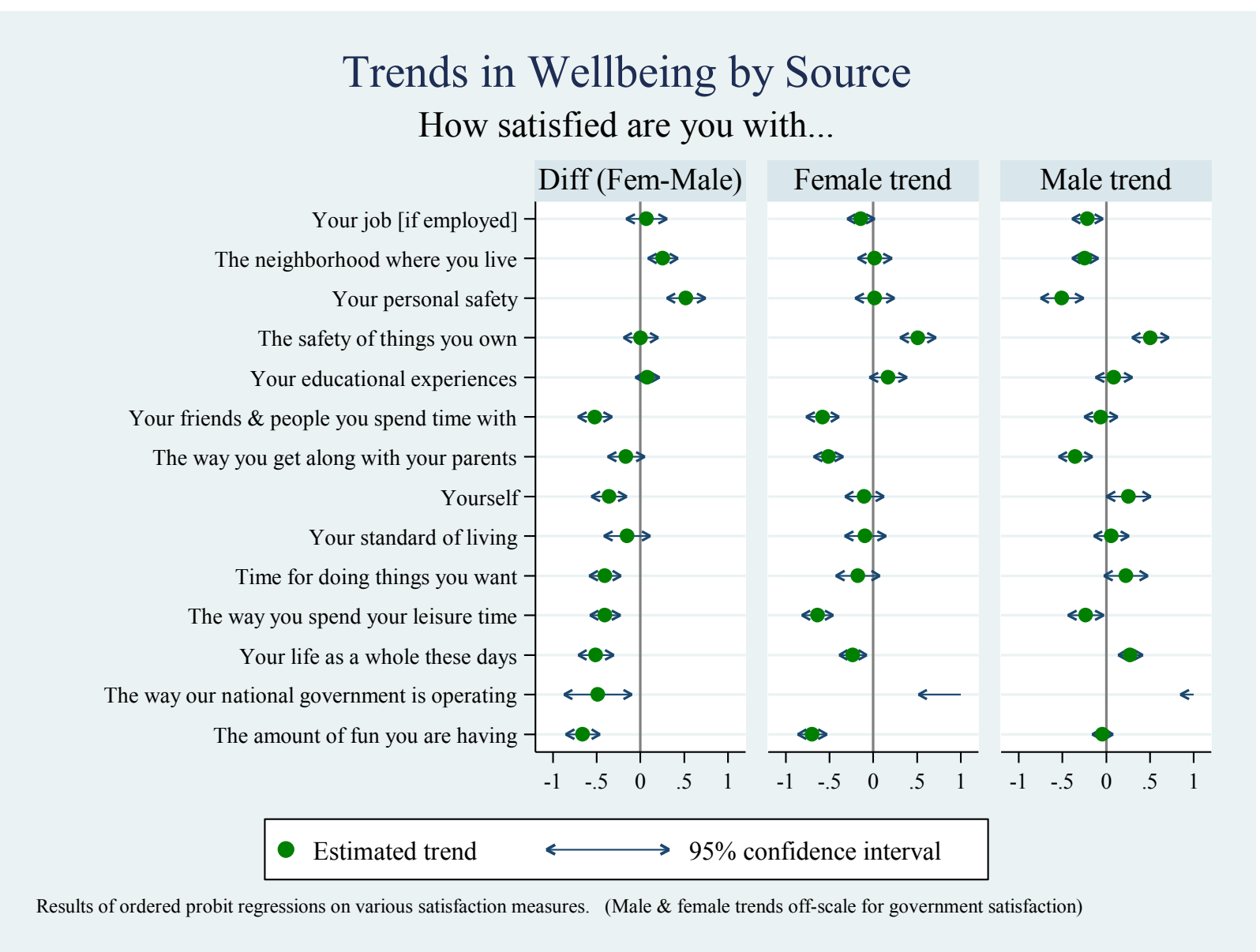

Source: Monitoring the Future $12^{\text {th }}$ grade study, conducted annually from 1976 to 2005, by the Survey Research Center in the Institute for Social Research at the University of Michigan.

Notes: Figure shows estimated coefficients and 95\% confidence intervals from estimating an ordered probit of domain-specific satisfaction (rated on a scale from 7="completely satisfied"; $4=$ "neutral" to 1="completely dissatisfied") on separate time trends and intercepts for men and women (as in equation [1]). Standard errors are clustered by year. 


\section{Trends in Preferences}

\section{How important is each of the following to you in your life?}

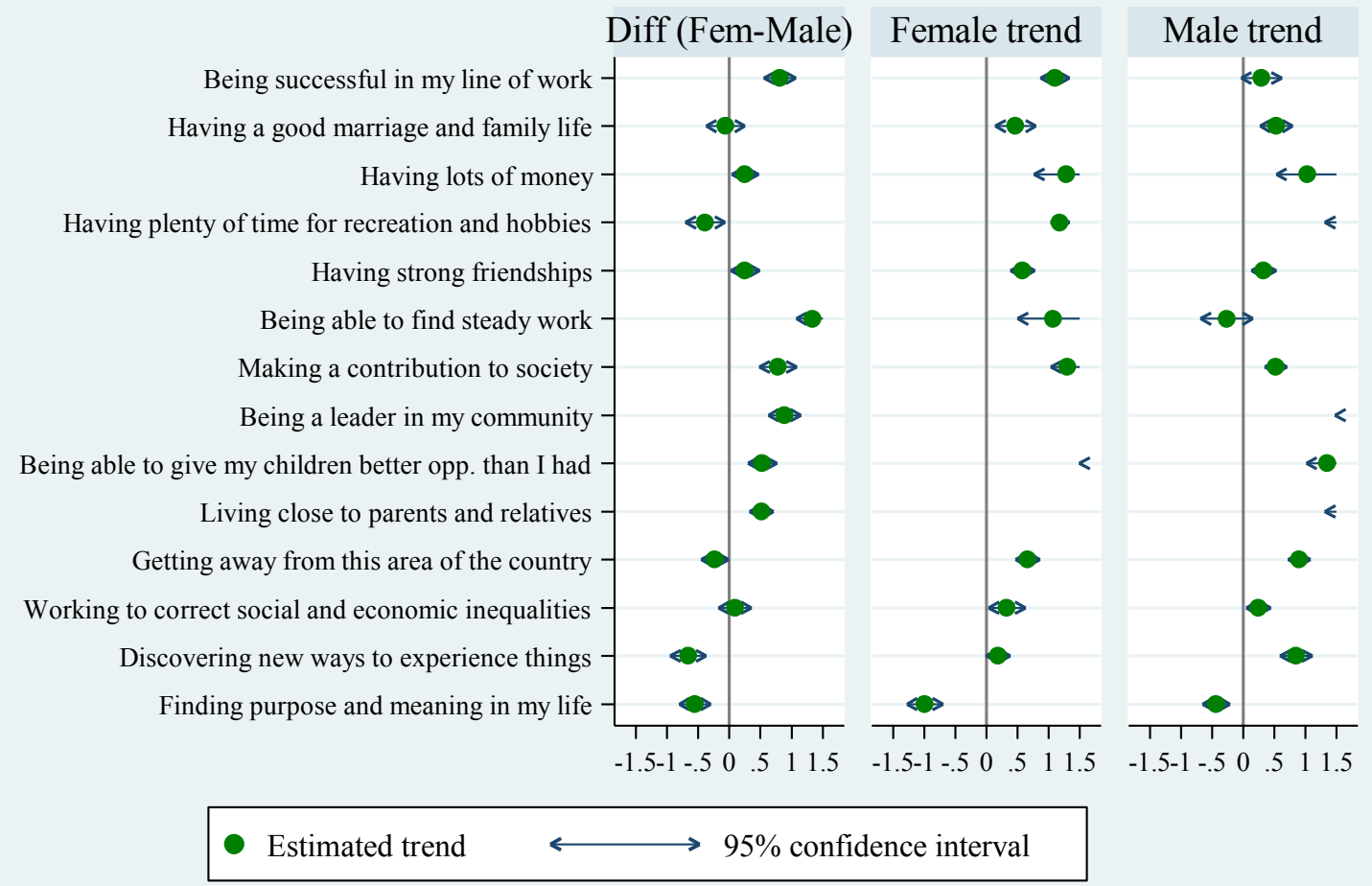

Results of ordered probit regressions. (Some coefficients off scale.)

Source: Monitoring the Future $12^{\text {th }}$ grade study, conducted annually from 1976 to 2005, by the Survey Research Center in the Institute for Social Research at the University of Michigan.

Notes: Figure shows estimated coefficients and 95\% confidence intervals from estimating an ordered probit of the importance of each domain (rated as either [1] "not important", [2] "somewhat important", [3] "quite important", [4] "extremely important") on separate time trends and intercepts for men and women (as in equation [1]). Standard errors are clustered by year. 
Figure 7: U.S. Suicide Rates, by Gender

\section{Suicide Rates in the United States}

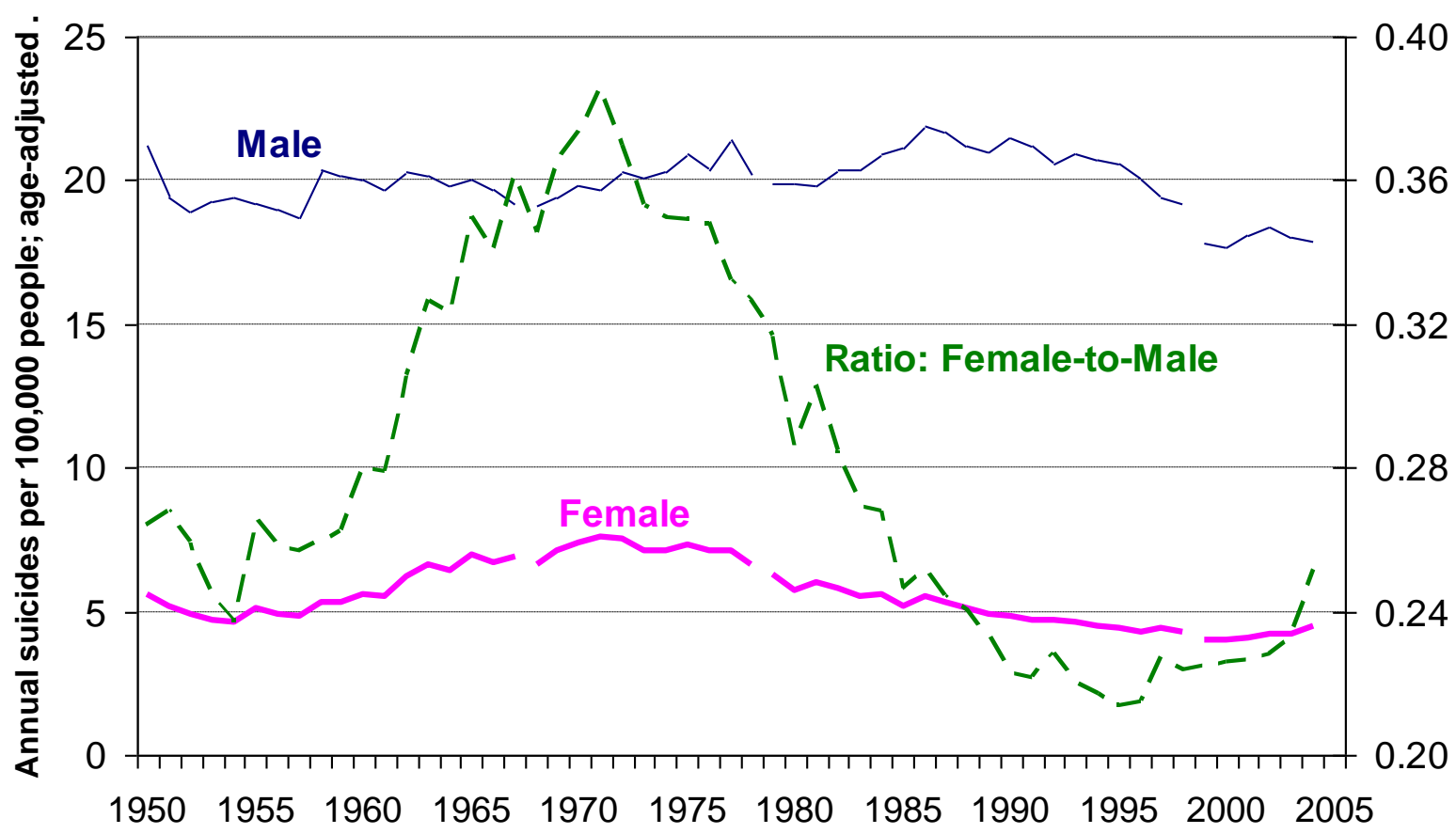

Source: Suicide data for 1950-1998 are from National Center for Health Statistics report "Vital Statistics: Mortality, Vol. 2." Data from 1999-2005 have been downloaded from the Center for Disease Control's Wonder system which accesses the NCHS “Compressed Mortality Files" (http://wonder.cdc.gov/). Notes: Series breaks correspond with changing ICD codes. 


\section{Table 1: Happiness Trends in the U.S. by Gender, General Social Survey}

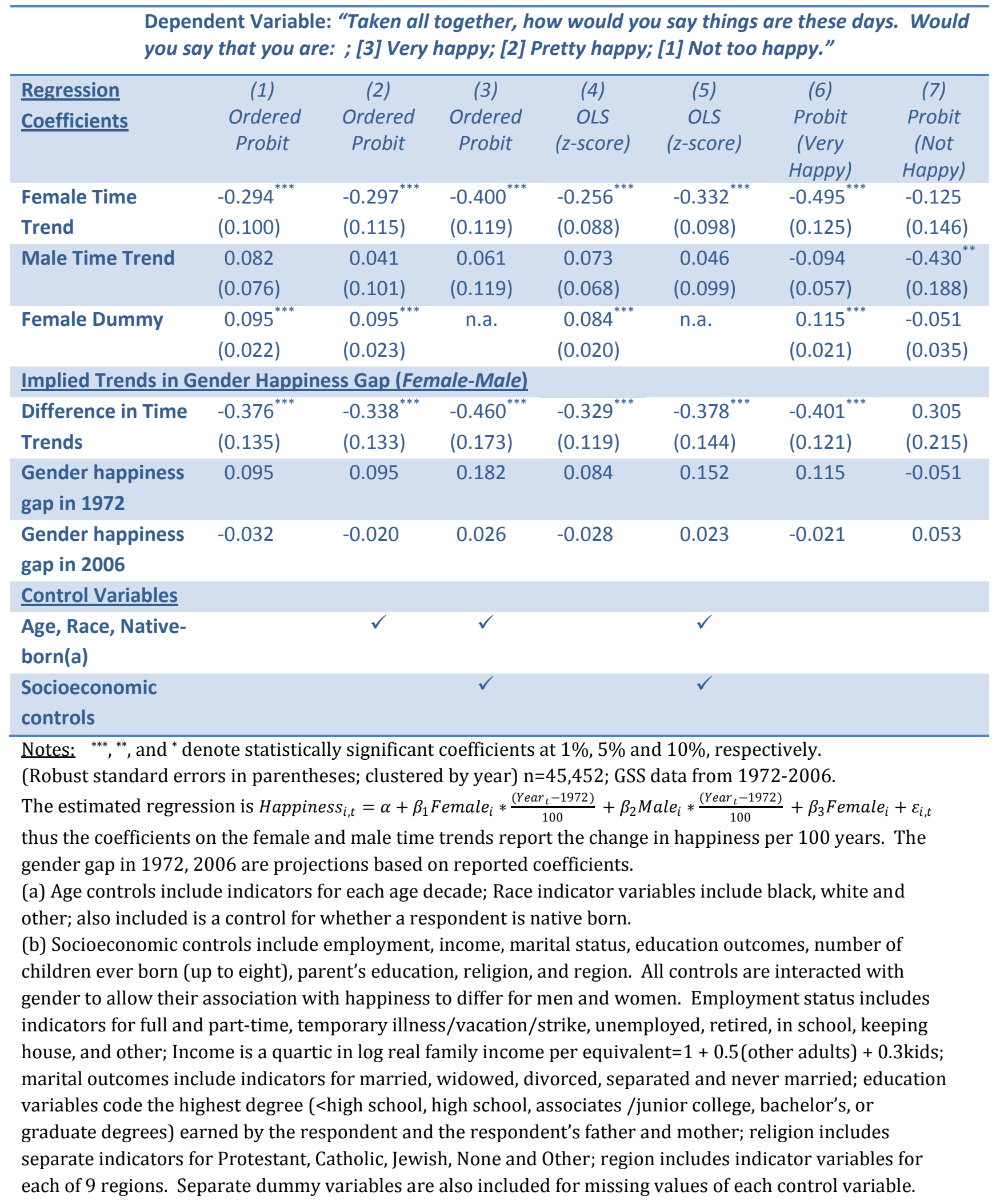


Table 2: Differential Happiness Trends in the U.S. by Race, General Social Survey

Ordered Probit Dependent Variable: "Taken all together, how would you say things are these days?

Regression Would you say that you are: [3] Very happy; [2] Pretty happy; [1] Not too happy."

\begin{tabular}{|c|c|c|c|c|c|c|}
\hline & \multicolumn{2}{|c|}{ Blacks } & \multicolumn{2}{|c|}{ Whites } & \multicolumn{2}{|c|}{ Non-Hispanic Whites } \\
\hline $\begin{array}{l}\text { Regression } \\
\text { Coefficients }\end{array}$ & Vo Controls & Full Controls & No Controls & Full Controls & No Controls & Full Controls \\
\hline $\begin{array}{l}\text { Female Time } \\
\text { Trend }\end{array}$ & $\begin{array}{l}0.698^{* * *} \\
(0.272)\end{array}$ & $\begin{array}{c}0.587^{*} \\
(0.334)\end{array}$ & $\begin{array}{l}-0.338^{* * *} \\
(0.102)\end{array}$ & $\begin{array}{l}-0.578^{* * *} \\
(0.122)\end{array}$ & $\begin{array}{l}-0.321^{* * *} \\
(0.119)\end{array}$ & $\begin{array}{l}-0.564^{* * *} \\
(0.138)\end{array}$ \\
\hline $\begin{array}{l}\text { Male Time } \\
\text { Trend }\end{array}$ & $\begin{array}{l}0.559^{* *} \\
(0.247)\end{array}$ & $\begin{array}{c}0.218 \\
(0.247)\end{array}$ & $\begin{array}{c}0.088 \\
(0.077)\end{array}$ & $\begin{array}{c}0.070 \\
(0.123)\end{array}$ & $\begin{array}{c}0.167 \\
(0.114)\end{array}$ & $\begin{array}{l}0.305^{* *} \\
(0.143)\end{array}$ \\
\hline $\begin{array}{l}\text { Female } \\
\text { Dummy }\end{array}$ & $\begin{array}{l}-0.088 \\
(0.080)\end{array}$ & n.a. & $\begin{array}{l}0.129^{* * *} \\
(0.024)\end{array}$ & n.a. & $\begin{array}{l}0.137^{* * *} \\
(0.029)\end{array}$ & n.a. \\
\hline \multicolumn{7}{|c|}{ Implied Trends in Gender Happiness Gap (Female-Male) } \\
\hline $\begin{array}{l}\text { Difference in } \\
\text { Time Trends }\end{array}$ & $\begin{array}{c}0.139 \\
(0.400)\end{array}$ & $\begin{array}{c}0.370 \\
(0.469)\end{array}$ & $\begin{array}{l}-0.427^{* * *} \\
(0.123)\end{array}$ & $\begin{array}{l}-0.648^{* * *} \\
(0.170)\end{array}$ & $\begin{array}{l}-0.489^{* * *} \\
(0.177)\end{array}$ & $\begin{array}{l}-0.869^{* * *} \\
(0.229)\end{array}$ \\
\hline $\begin{array}{l}\text { Gender } \\
\text { happiness gap in } \\
1972\end{array}$ & -0.088 & -0.029 & 0.129 & 0.233 & 0.137 & 0.286 \\
\hline $\begin{array}{l}\text { Gender } \\
\text { happiness gap in } \\
2006\end{array}$ & -0.040 & 0.097 & -0.016 & 0.013 & -0.029 & -0.009 \\
\hline
\end{tabular}

Notes: ${ }^{* * *},{ }^{* *}$, and ${ }^{*}$ denote statistically significant coefficients at $1 \%, 5 \%$ and $10 \%$, respectively.

(Robust standard errors in parentheses; clustered by year)

$\mathrm{n}=5,605$ blacks, 38,136 whites, 27,383 non-Hispanic whites; GSS data from 1972-2006.

The estimated no controls regression is Happiness $_{i, t}=\alpha+\beta_{1}$ Female $_{i} * \frac{\left(\text { Year }_{t}-1972\right)}{100}+\beta_{2}$ Male $_{i} * \frac{\left(\text { Year }_{t}-1972\right)}{100}+$

$\beta_{3}$ Female $_{i}+\varepsilon_{i, t}$ thus the coefficients on the female and male time trends report the change in happiness per 100 years.

The gender gap in 1972, 2006 are projections based on reported coefficients.

No controls regression specification as in column one of Table 1; Full controls, includes interaction of individual-level observables with gender, as in the final column of Table 1. 
Table 3: Trends in Happiness by Demographic Group, United States (Whites Only)

\begin{tabular}{|c|c|c|c|c|c|c|}
\hline \multirow[t]{3}{*}{ Ordered Probit } & \multicolumn{6}{|c|}{ Estimated Time Trend in Happiness } \\
\hline & \multicolumn{3}{|c|}{ No Controls } & \multicolumn{3}{|c|}{ Full Controls } \\
\hline & Women & Men & Difference & Women & Men & Difference \\
\hline \multirow[t]{2}{*}{ All Whites } & $-0.338^{* * *}$ & 0.088 & $-0.427^{* * *}$ & $-0.578^{* * *}$ & 0.070 & $-0.648 * * *$ \\
\hline & $(0.102)$ & $(0.077)$ & $(0.123)$ & $(0.122)$ & $(0.123)$ & $(0.170)$ \\
\hline \multicolumn{7}{|c|}{ Panel A: By Age } \\
\hline \multirow[t]{2}{*}{$18-29$} & -0.101 & $0.342^{* *}$ & $-0.444^{* *}$ & -0.015 & $0.484^{* * *}$ & $-0.499^{*}$ \\
\hline & $(0.181)$ & $(0.169)$ & $(0.225)$ & $(0.227)$ & $(0.184)$ & $(0.307)$ \\
\hline \multirow[t]{2}{*}{$30-44$} & $-0.410^{*}$ & 0.064 & $-0.474^{*}$ & $-0.487^{* *}$ & 0.267 & $-0.754^{* * *}$ \\
\hline & $(0.216)$ & $(0.150)$ & $(0.270)$ & $(0.220)$ & $(0.187)$ & $(0.274)$ \\
\hline \multirow[t]{2}{*}{$45-59$} & $-0.500^{* * *}$ & $-0.284^{* *}$ & -0.216 & $-0.750^{* * *}$ & $-0.294^{* *}$ & $-0.456^{* *}$ \\
\hline & $(0.204)$ & $(0.121)$ & $(0.185)$ & $(0.208)$ & $(0.143)$ & $(0.216)$ \\
\hline \multirow[t]{2}{*}{$60+$} & $-0.329^{*}$ & 0.089 & $-0.418^{* *}$ & $-0.988^{* * *}$ & -0.155 & $-0.832^{* * *}$ \\
\hline & $(0.173)$ & $(0.184)$ & $(0.214)$ & $(0.214)$ & $(0.206)$ & $(0.264)$ \\
\hline $\begin{array}{l}\text { p-value of between } \\
\text { row differences }\end{array}$ & 0.524 & 0.007 & 0.584 & 0.005 & 0.001 & 0.529 \\
\hline \multicolumn{7}{|c|}{ Panel B: By Employment Status } \\
\hline \multirow[t]{2}{*}{ Employed } & $-0.409^{* * *}$ & 0.213 & $-0.622^{* * *}$ & $-0.639^{* * *}$ & -0.151 & $-0.488^{* *}$ \\
\hline & $(0.124)$ & $(0.163)$ & $(0.171)$ & $(0.132)$ & (0.149) & $(0.201)$ \\
\hline \multirow[t]{2}{*}{ Not employed } & -0.216 & 0.116 & $-0.332^{*}$ & $-0.460^{* * *}$ & 0.184 & $-0.644^{* * *}$ \\
\hline & (0.153) & $(0.102)$ & $(0.175)$ & $(0.175)$ & $(0.146)$ & $(0.194)$ \\
\hline $\begin{array}{l}\text { p-value of between } \\
\text { row differences }\end{array}$ & 0.314 & 0.640 & 0.240 & 0.374 & 0.081 & 0.433 \\
\hline \multicolumn{7}{|c|}{ Panel C: By Marital Status } \\
\hline \multirow[t]{2}{*}{ Married } & -0.049 & $0.459^{* * *}$ & $-0.508^{* * *}$ & $-0.589^{* * *}$ & 0.005 & $-0.594^{* * *}$ \\
\hline & (0.149) & $(0.101)$ & $(0.164)$ & $(0.184)$ & $(0.141)$ & $(0.220)$ \\
\hline \multirow[t]{2}{*}{ Widowed } & 0.103 & 0.764 & -0.661 & $-0.599^{* * *}$ & 0.485 & $-1.085^{*}$ \\
\hline & $(0.234)$ & $(0.538)$ & $(0.624)$ & $(0.230)$ & $(0.528)$ & $(0.589)$ \\
\hline Divorced / & -0.069 & $0.626^{* * *}$ & $-0.695^{* * *}$ & $-0.588^{* *}$ & 0.229 & $-0.818^{* * *}$ \\
\hline Separated & (0.289) & $(0.218)$ & $(0.241)$ & $(0.269)$ & $(0.222)$ & $(0.262)$ \\
\hline \multirow[t]{2}{*}{ Never married } & -0.365 & 0.291 & $-0.657^{* * *}$ & $-0.516^{*}$ & 0.131 & $-0.647^{* *}$ \\
\hline & $(0.297)$ & $(0.190)$ & $(0.265)$ & $(0.283)$ & $(0.178)$ & $(0.295)$ \\
\hline p-value of between & 0.591 & 0.686 & 0.927 & 0.993 & 0.600 & 0.861 \\
\hline \multicolumn{7}{|c|}{ Panel D: By Fertility (live births) } \\
\hline \multirow[t]{2}{*}{ Kids } & -0.175 & 0.121 & -0.295 & $-0.397^{*}$ & 0.046 & -0.443 \\
\hline & (0.191) & $(0.166)$ & $(0.243)$ & $(0.211)$ & (0.159) & $(0.274)$ \\
\hline \multirow[t]{2}{*}{ No Kids } & $-0.386^{* * *}$ & 0.116 & $-0.502^{* * *}$ & $-0.640^{* * *}$ & 0.082 & $-0.722^{* * *}$ \\
\hline & $(0.128)$ & (0.104) & $(0.143)$ & $(0.132)$ & $(0.152)$ & $(0.166)$ \\
\hline $\begin{array}{l}\text { p-value of between } \\
\text { row differences }\end{array}$ & 0.391 & 0.982 & 0.466 & 0.278 & 0.858 & 0.256 \\
\hline
\end{tabular}




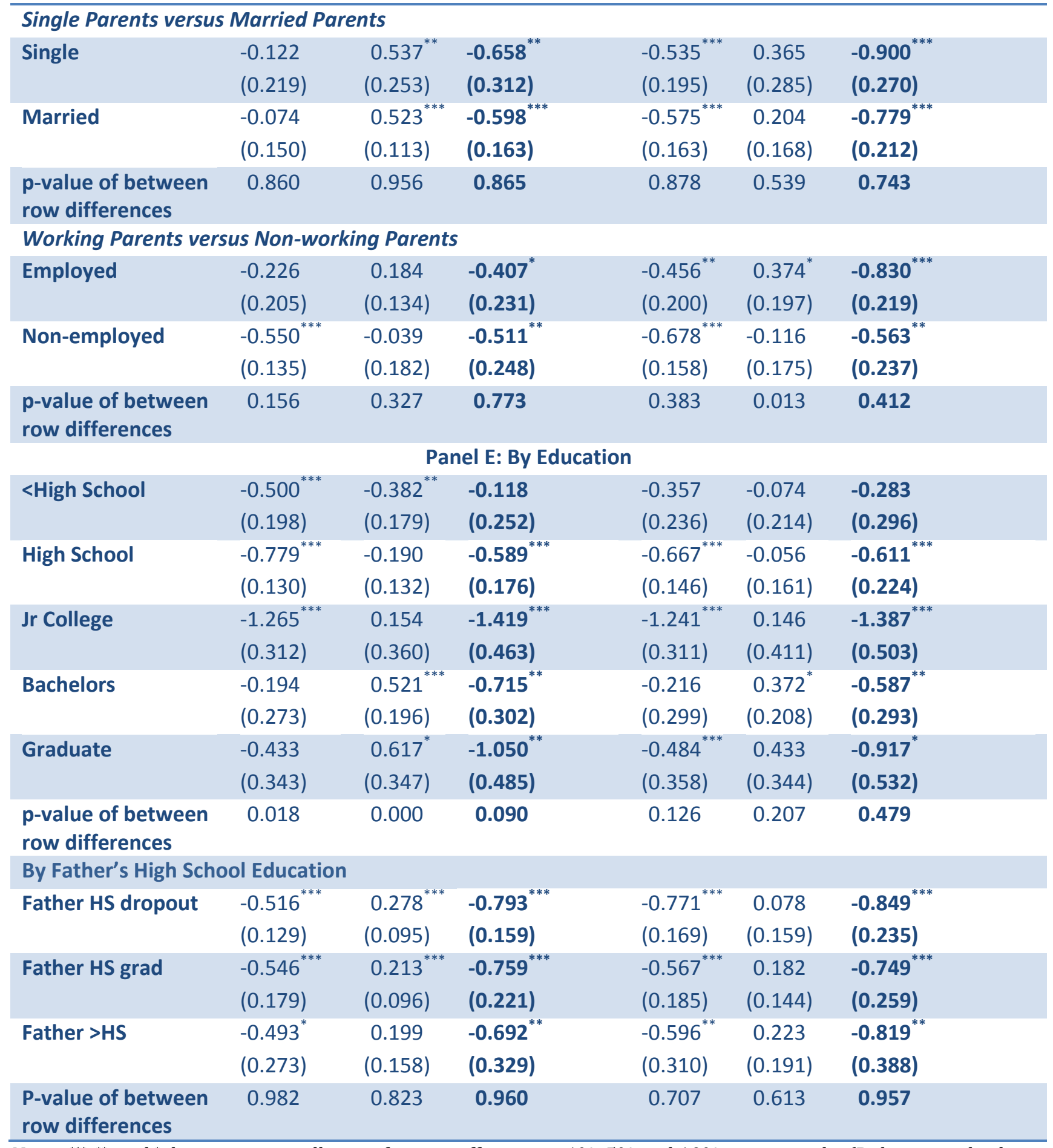

Notes: $^{* * *},{ }^{* *}$, and ${ }^{*}$ denote statistically significant coefficients at $1 \%, 5 \%$ and $10 \%$, respectively. (Robust standard errors in parentheses; clustered by year); $n=38,136$ whites (the exact sample varies slightly for each demographic group due to missing information); GSS data from 1972-2006. Each block shows the results of two regressions. The first two columns are the coefficients on female time and male*time each interacted with dummy variables for each specific panel category from an ordered probit that also controls for a female dummy, as in column one of Table 1. Time is measured per 1/100 of a year; as such the coefficients on the time trends report the change in happiness per 100 years. The third column shows the difference between the male and female time trends. The last three columns repeat this exercise but add individual-level controls interacted with gender, as in the final column of Table 1. The bottom row of each block shows p-values from an F-test of the equality of the relevant trends. 
Table 4: Life Satisfaction Trends by Country, Eurobarometer Survey

\begin{tabular}{|c|c|c|c|c|c|c|c|}
\hline \multicolumn{3}{|l|}{ Ordered Probit } & \multicolumn{5}{|c|}{ Estimated Time Trend in Life Satisfaction } \\
\hline & \multirow[t]{2}{*}{ \#Surveys } & \multicolumn{3}{|c|}{ No Controls } & \multicolumn{3}{|c|}{ Full Controls $^{(a)}$} \\
\hline & & Women & Men & Difference & Women & Men & Difference \\
\hline $\begin{array}{l}\text { All EU } \\
\text { (Life sat.) }\end{array}$ & 47 & $\begin{array}{l}0.522^{* * *} \\
(0.149)\end{array}$ & $\begin{array}{l}0.729^{* * *} \\
(0.135)\end{array}$ & $\begin{array}{l}-0.207^{* * *} \\
(0.067)\end{array}$ & $\begin{array}{l}0.666^{* * *} \\
(0.155)\end{array}$ & $\begin{array}{l}0.868^{* * *} \\
(0.192)\end{array}$ & $\begin{array}{l}-0.201^{*} \\
(0.114)\end{array}$ \\
\hline All EU (Happiness) & 14 & $\begin{array}{l}1.352^{* *} \\
(0.667)\end{array}$ & $\begin{array}{l}1.725^{* * *} \\
(0.550)\end{array}$ & $\begin{array}{l}-0.373 \\
(0.246)\end{array}$ & $\begin{array}{l}1.554^{* *} \\
(0.782)\end{array}$ & $\begin{array}{l}2.202^{* * *} \\
(0.613)\end{array}$ & $\begin{array}{l}-0.648 \\
(0.435)\end{array}$ \\
\hline \multicolumn{8}{|c|}{ Life Satisfaction By Country } \\
\hline Belgium & 47 & $\begin{array}{l}-1.421^{* * *} \\
(0.257)\end{array}$ & $\begin{array}{l}-1.325^{* * *} \\
(0.245)\end{array}$ & $\begin{array}{l}-0.097 \\
(0.113)\end{array}$ & $\begin{array}{l}-1.240^{* * *} \\
(0.361)\end{array}$ & $\begin{array}{l}-1.535^{* * *} \\
(0.334)\end{array}$ & $\begin{array}{c}0.296 \\
(0.229)\end{array}$ \\
\hline Denmark & 47 & $\begin{array}{l}1.179^{* * *} \\
(0.193)\end{array}$ & $\begin{array}{l}1.467^{* * *} \\
(0.192)\end{array}$ & $\begin{array}{l}-0.288^{* *} \\
(0.136)\end{array}$ & $\begin{array}{l}1.222^{* * *} \\
(0.264)\end{array}$ & $\begin{array}{l}1.382^{* * *} \\
(0.242)\end{array}$ & $\begin{array}{l}-0.159 \\
(0.204)\end{array}$ \\
\hline France & 47 & $\begin{array}{c}0.413^{*} \\
(0.249)\end{array}$ & $\begin{array}{l}0.961^{* * *} \\
(0.235)\end{array}$ & $\begin{array}{l}-0.548^{* * *} \\
(0.104)\end{array}$ & $\begin{array}{c}0.897 \\
(0.259)\end{array}$ & $\begin{array}{l}1.281^{* * *} \\
(0.271)\end{array}$ & $\begin{array}{l}-0.384^{* *} \\
(0.180)\end{array}$ \\
\hline $\begin{array}{l}\text { Great Britain (inc. } \\
\text { N. Ireland) }\end{array}$ & 47 & $\begin{array}{c}0.137 \\
(0.124)\end{array}$ & $\begin{array}{l}0.247^{* *} \\
(0.123)\end{array}$ & $\begin{array}{l}-0.110 \\
(0.103)\end{array}$ & $\begin{array}{l}0.432^{* * *} \\
(0.161)\end{array}$ & $\begin{array}{l}0.540^{* * *} \\
(0.212)\end{array}$ & $\begin{array}{l}-0.108 \\
(0.204)\end{array}$ \\
\hline Greece & 36 & $\begin{array}{l}-0.589 \\
(0.427)\end{array}$ & $\begin{array}{l}-0.204 \\
(0.425)\end{array}$ & $\begin{array}{l}-0.386^{* *} \\
(0.194)\end{array}$ & $\begin{array}{l}-0.470 \\
(0.486)\end{array}$ & $\begin{array}{l}-0.179 \\
(0.474)\end{array}$ & $\begin{array}{l}-0.291 \\
(0.306)\end{array}$ \\
\hline Ireland & 47 & $\begin{array}{l}-0.155 \\
(0.293)\end{array}$ & $\begin{array}{c}0.032 \\
(0.308)\end{array}$ & $\begin{array}{l}-0.187^{*} \\
(0.100)\end{array}$ & $\begin{array}{l}-0.503^{* *} \\
(0.244)\end{array}$ & $\begin{array}{l}-0.022 \\
(0.255)\end{array}$ & $\begin{array}{l}-0.450^{* *} \\
(0.206)\end{array}$ \\
\hline Italy & 47 & $\begin{array}{l}1.714^{* * *} \\
(0.219)\end{array}$ & $\begin{array}{c}2.177^{* * *} \\
(0.201)\end{array}$ & $\begin{array}{l}-0.463^{* * *} \\
(0.153)\end{array}$ & $\begin{array}{l}1.716^{* * *} \\
(0.172)\end{array}$ & $\begin{array}{l}2.123^{* * *} \\
(0.248)\end{array}$ & $\begin{array}{l}-0.408^{* *} \\
(0.193)\end{array}$ \\
\hline Luxembourg & 47 & $\begin{array}{c}0.184 \\
(0.292)\end{array}$ & $\begin{array}{c}0.879^{* * *} \\
(0.215)\end{array}$ & $\begin{array}{l}-0.696^{* * *} \\
(0.260)\end{array}$ & $\begin{array}{l}-0.239 \\
(0.317)\end{array}$ & $\begin{array}{c}0.734^{* * *} \\
(0.209)\end{array}$ & $\begin{array}{l}-0.972^{* * *} \\
(0.301)\end{array}$ \\
\hline Netherlands & 47 & $\begin{array}{c}0.311 \\
(0.208)\end{array}$ & $\begin{array}{c}0.694^{* * *} \\
(0.154)\end{array}$ & $\begin{array}{l}-0.383^{* * *} \\
(0.137)\end{array}$ & $\begin{array}{c}0.505 \\
(0.364)\end{array}$ & $\begin{array}{l}1.000^{* * *} \\
(0.260)\end{array}$ & $\begin{array}{l}-0.495 \\
(0.325)\end{array}$ \\
\hline Portugal & 28 & $\begin{array}{l}-0.081 \\
(0.593)\end{array}$ & $\begin{array}{c}1.275^{* *} \\
(0.598)\end{array}$ & $\begin{array}{l}-1.356^{* * *} \\
(0.138)\end{array}$ & $\begin{array}{l}-0.118 \\
(0.593)\end{array}$ & $\begin{array}{c}1.646^{* *} \\
(0.730)\end{array}$ & $\begin{array}{l}-1.529^{* * *} \\
(0.314)\end{array}$ \\
\hline Spain & 28 & $\begin{array}{c}0.309 \\
(0.484)\end{array}$ & $\begin{array}{c}0.532 \\
(0.512)\end{array}$ & $\begin{array}{l}-0.223 \\
(0.226)\end{array}$ & $\begin{array}{c}1.107^{*} \\
(0.634)\end{array}$ & $\begin{array}{c}.780 \\
(0.516)\end{array}$ & $\begin{array}{c}0.327 \\
(0.360)\end{array}$ \\
\hline West Germany & 47 & $\begin{array}{c}0.468 \\
(0.291)\end{array}$ & $\begin{array}{c}0.160 \\
(0.213)\end{array}$ & $\begin{array}{c}0.308^{* *} \\
(0.154)\end{array}$ & $\begin{array}{c}0.392 \\
(0.362)\end{array}$ & $\begin{array}{c}0.383 \\
(0.306)\end{array}$ & $\begin{array}{c}0.009 \\
(0.255)\end{array}$ \\
\hline
\end{tabular}

Notes: ${ }^{* * *}, * *$ and ${ }^{*}$ denote statistically significant coefficients at $1 \%, 5 \%$ and $10 \%$, respectively.

(Robust standard errors in parentheses; clustered by Eurobarometer survey round.)

Eurobarometer data from the 1973-2002 ZEW Eurobarometer Trend File. Those countries entering the Eurobarometer in the 1990s not separately shown. Life satisfaction: $n=636,400$ in 47 survey rounds, drawn from 1973, 1975-2002. Happiness: n=134,504 in 14 survey rounds, drawn from 1975-1979, 1982-1986. Country samples are weighted to be representative of the entire EU. As with the US data, time is measured per 1/100 of a year; as such the coefficients on the time trends report the change in happiness per 100 years.

(a) Controls include fixed effects for: 10-year age groups; marital and employment status; education; nation and for missing values of each control variable. 


\section{Table 5: Trends in Well-being by Domain, GSS}

\section{Estimated Time Trend in Well-being}

\begin{tabular}{|c|c|c|c|c|c|c|}
\hline \multirow{2}{*}{$\begin{array}{l}\text { Question } \\
\text { Sample }\end{array}$} & \multicolumn{3}{|c|}{ No Controls } & \multicolumn{3}{|c|}{ Full Controls } \\
\hline & Women & Men & Difference & Women & Men & Difference \\
\hline $\begin{array}{l}\text { Panel A: } \\
\text { Job Satisfaction }\end{array}$ & \multicolumn{6}{|c|}{$\begin{array}{l}\text { "On the whole, how satisfied are you with the work you do? Would you say you are [4] Very } \\
\text { satisfied; [3] Moderately satisfied; [2] a little dissatisfied, or [1] Very dissatisfied"? }\end{array}$} \\
\hline All & 0.181 & 0.059 & 0.123 & 0.119 & 0.120 & -0.000 \\
\hline respondents & $(0.141)$ & $(0.146)$ & $(0.131)$ & (0.195) & (0.212) & $(0.246)$ \\
\hline If market & -0.047 & 0.032 & -0.078 & -0.325 & 0.082 & $-0.407^{* *}$ \\
\hline work & (0.157) & (0.129) & (0.139) & (0.218) & (0.206) & $(0.262)$ \\
\hline If keeping & $0.566^{*}$ & $1.983^{* * *}$ & $-1.417^{* *}$ & $1.043^{* * *}$ & 2.073 & -1.030 \\
\hline house & $(0.310)$ & $(0.618)$ & $(0.692)$ & $(0.365)$ & $(1.464)$ & (1.494) \\
\hline $\begin{array}{l}\text { Panel B: } \\
\text { Family finances }\end{array}$ & \multicolumn{6}{|c|}{$\begin{array}{l}\text { "We are interested in how people are getting along financially these days. So far as you and } \\
\text { your family are concerned, would you say that you are [3] Pretty well satisfied with your } \\
\text { present financial situation; [2] More or less satisfied; or [1] Not satisfied at all?" }\end{array}$} \\
\hline \multirow[t]{2}{*}{ All adults } & $-0.184^{*}$ & 0.140 & $-0.324^{* * *}$ & $-0.614^{* * *}$ & $-0.417^{*}$ & $-0.197^{*}$ \\
\hline & $(0.113)$ & (0.119) & $(0.064)$ & $(0.166)$ & (0.203) & $(0.104)$ \\
\hline \multirow[t]{2}{*}{ Married } & $0.204^{* *}$ & $0.516^{* * *}$ & $-0.312^{* * *}$ & $-0.587^{* * *}$ & $-0.474^{*}$ & -0.114 \\
\hline & (0.089) & $(0.136)$ & $(0.084)$ & $(0.164)$ & (0.259) & $(0.141)$ \\
\hline \multirow[t]{2}{*}{ Single } & $-0.555^{* * *}$ & -0.249 & -0.306 & $-0.561^{* * *}$ & -0.240 & $-0.321^{* *}$ \\
\hline & $(0.185)$ & $(0.180)$ & $(0.208)$ & $(0.224)$ & (0.181) & $(0.165)$ \\
\hline $\begin{array}{l}\text { Panel C: } \\
\text { Marital } \\
\text { happiness }\end{array}$ & \multicolumn{6}{|c|}{$\begin{array}{l}\text { If currently married: "Taking things all together, how would you describe your marriage? Would } \\
\text { you say that your marriage is [3] Very happy; [2] Pretty happy; or [1] Not too happy }\end{array}$} \\
\hline Currently & $-0.376^{* * *}$ & $-0.350^{* *}$ & -0.026 & $-0.568^{* * *}$ & -0.323 & -0.245 \\
\hline married & $(0.149)$ & $(0.166)$ & $(0.205)$ & $(0.188)$ & (0.217) & (0.279) \\
\hline $\begin{array}{l}\text { Panel D: } \\
\text { Health }\end{array}$ & \multicolumn{6}{|c|}{ "Would you say your own health, in general, is [4] Excellent; [3] Good; [2] Fair, or [1] Poor?" } \\
\hline \multirow[t]{2}{*}{ All adults } & $0.370^{* * *}$ & 0.005 & $0.365^{* * *}$ & $-0.241^{* *}$ & $-0.273^{*}$ & 0.032 \\
\hline & $(0.118)$ & (0.087) & $(0.130)$ & $(0.110)$ & $(0.121)$ & (0.179) \\
\hline
\end{tabular}

Notes: ${ }^{* * *}, * *$ and ${ }^{*}$ denote statistically significant coefficients at $1 \%, 5 \%$ and $10 \%$, respectively.

(Robust standard errors in parentheses; clustered by year)

GSS data from 1972-2006; sample sizes vary by data availability.

Each row examines a different subset of the total white population and shows the results of two regressions.

The first three columns are the coefficients on female*time and male*time and the difference in these estimates, from an ordered probit of each satisfaction measure, controlling for a female dummy, as in column one of Table 1. Time is measured per $1 / 100$ of a year; as such the coefficients on the time trends report the change in happiness per 100 years. The last three columns report the same coefficients, but from a specification that includes individual-level controls interacted with gender, as in the final column of Table 1. 


\section{Table 6: Trends in Satisfaction by Domain, GSS}

\section{Estimated Time Trend in Well-being}

For each area of life I am going to name tell me the number that shows how much satisfaction you get from that area: [7] A very great deal; [6] A great deal; [5] Quite a bit; [4] A fair amount; [3] Some; [2] A little; [1] None

\begin{tabular}{|c|c|c|c|c|c|c|}
\hline Question & \multicolumn{3}{|c|}{ No Controls } & \multicolumn{3}{|c|}{$\underline{\text { Full Controls }}$} \\
\hline Sample & Women & Men & Difference & Women & Men & Difference \\
\hline \multicolumn{7}{|c|}{ The city or place you live in } \\
\hline All & $-0.199^{*}$ & -0.151 & -0.048 & $-0.529^{*}$ & -0.120 & $-0.409^{* *}$ \\
\hline respondents & $(0.122)$ & $(0.156)$ & $(0.146)$ & $(0.321)$ & $(0.322)$ & $(0.211)$ \\
\hline \multicolumn{7}{|c|}{ Your non-working activities--hobbies and so on } \\
\hline \multirow[t]{2}{*}{ All adults } & $0.428^{* * *}$ & 0.175 & 0.253 & -0.245 & -0.470 & 0.224 \\
\hline & $(0.166)$ & $(0.205)$ & $(0.158)$ & $(0.201)$ & $(0.321)$ & $(0.257)$ \\
\hline \multicolumn{7}{|c|}{ Your family life } \\
\hline \multirow[t]{2}{*}{ All adults } & 0.073 & -0.091 & 0.164 & 0.029 & 0.352 & -0.324 \\
\hline & $(0.175)$ & $(0.184)$ & $(0.212)$ & $(0.269)$ & $(0.368)$ & $(0.412)$ \\
\hline \multicolumn{7}{|c|}{ Your friendships } \\
\hline \multirow[t]{2}{*}{ All adults } & $0.373^{*}$ & -0.245 & $0.617^{* * *}$ & 0.253 & -0.306 & $0.560^{*}$ \\
\hline & (0.198) & $(0.227)$ & $(0.245)$ & $(0.256)$ & $(0.424)$ & $(0.297)$ \\
\hline \multicolumn{7}{|c|}{ Your health and physical condition } \\
\hline \multirow[t]{2}{*}{ All adults } & -0.127 & -0.229 & 0.101 & $-0.824^{* * *}$ & $-0.612^{* *}$ & -0.212 \\
\hline & (0.173) & $(0.168)$ & $(0.170)$ & $(0.335)$ & $(0.264)$ & $(0.327)$ \\
\hline
\end{tabular}

Notes: ${ }^{* * *},{ }^{* *}$, and ${ }^{*}$ denote statistically significant coefficients at $1 \%, 5 \%$ and $10 \%$, respectively.

(Robust standard errors in parentheses; clustered by year)

GSS data from 1972-2006; sample sizes vary by data availability.

Each row examines a different subset of the total white population and shows the results of two regressions.

The first three columns are the coefficients on female*time and male*time and the difference in these estimates, from an ordered probit of each satisfaction measure, controlling for a female dummy, as in column one of Table 1 . Time is measured per $1 / 100$ of a year; as such the coefficients on the time trends report the change in happiness per 100 years. The last three columns report the same coefficients, but from a specification that controls for a rich array of individual-level characteristics interacted with gender, as in the final column of Table 1. 